\title{
Structural insight into tanapoxvirus mediated inhibition of apoptosis
}

Chathura D. Suraweera ${ }^{1}$, Mohd Ishtiaq Anasir ${ }^{1 \$}$, Srishti Chugh ${ }^{1 \&}$, Airah Javorsky ${ }^{1}$, Rachael E. Impey ${ }^{1}$, Mohammad Hasan Zadeh ${ }^{1}$, Tatiana P. Soares da $\operatorname{Costa}^{1}$, Mark G. Hinds ${ }^{2 \#}$ and Marc Kvansakul ${ }^{\text {*\# }}$

${ }^{1}$ La Trobe Institute for Molecular Science, Department of Biochemistry and Genetics, La Trobe University, VIC 3086, Australia

${ }^{2}$ Bio21 Molecular Science and Biotechnology Institute, The University of Melbourne, Parkville, Australia

${ }^{\&}$ Current address: CSL Limited, Parkville, Victoria, Australia

${ }^{\$}$ Current address: Centre for Virus and Vaccine Research, Sunway University, Malaysia

${ }^{\#}$ Co-senior author

*To whom correspondence should be addressed: MK, Department of Biochemistry \& Genetics, La Trobe University, Melbourne, VIC 3086, Australia. Ph: +61 39479 2263; Fax: +61 39479 2467; E-mail: m.kvansakul@1atrobe.edu.au

Running title: Tanapoxvirus $16 \mathrm{~L}$ inhibits apoptosis

Keywords: Poxvirus, tanapoxvirus, apoptosis, X-ray crystallography, isothermal titration calorimetry, Bcl-2

Abbreviations: tanapoxvirus (TANV); isothermal titration calorimetry (ITC); B-cell lymphoma 2 (Bcl-2); Bcl-2 homology (BH); 


\begin{abstract}
Premature programmed cell death or apoptosis of cells is a strategy utilized by multicellular organisms to counter microbial threats. Tanapoxvirus (TANV) is a large double-stranded DNA virus belonging to the poxviridae that causes mild Monkeypox-like infections in humans and primates. TANV encodes for a putative apoptosis inhibitory protein $16 \mathrm{~L}$. We show that TANV16L is able to bind to a range of peptides spanning the $\mathrm{BH} 3$ motif of human pro-apoptotic Bcl-2 proteins, and is able to counter growth arrest of yeast induced by human Bak and Bax. We then determined the crystal structures of TANV16L bound to three identified interactors, Bax, Bim and Puma BH3. TANV16L adopts a globular Bcl-2 fold comprising $7 \alpha$-helices, and utilizes the canonical $\mathrm{Bcl}-2$ binding groove to engage proapoptotic host cell Bcl-2 proteins. Unexpectedly, TANV16L is able to adopt both a monomeric as well as a domain-swapped dimeric topology where the $\alpha 1$ helix from one protomer is swapped into a neighbouring unit. Despite adopting two different oligomeric forms, the canonical ligand binding groove in TANV16L remains unchanged from monomer to domain-swapped dimer. Our results provide a structural and mechanistic basis for tanapoxvirus mediated inhibition of host cell apoptosis, and reveal the capacity of Bcl-2 proteins to adopt differential oligomeric states whilst maintaining the canonical ligand binding groove in an unchanged state.
\end{abstract}




\section{Introduction}

Tanapoxvirus [1] is a large double-stranded DNA virus and member of the genus yatapoxvirus, which belongs to the poxviridae family. Tanapoxvirus (TANV) causes mild monkeypox-like infections in humans as well as primates with symptoms that include fever and skin lesions [2]. Tanapoxvirus encodes a range of immune modulatory proteins such as TNF inhibitors [3], as well as a putative B-cell lymphoma-2 (Bcl-2) homolog [4]. Bcl-2 proteins constitute a large family of proteins that primarily control programmed cell death, or apoptosis, in higher organisms [5] and are evolutionarily ancient [6]. The family comprises both prosurvival and proapoptotic members, which are characterized by the presence of one or more of four $\mathrm{Bcl}-2$ homology or $\mathrm{BH}$ motifs and a transmembrane anchor region [7]. The mammalian prosurvival Bcl-2 members comprise Bcl-2, Bcl-w, Bcl-x $\mathrm{L}, \mathrm{Mcl}-1, \mathrm{~A} 1$ and Bcl-b, and maintain host cell survival. In contrast, proapoptotic Bcl-2 family members are subdivided into two separate groups, the multimotif executors that comprise Bak, Bax and Bok, and a second group, the BH3-only proteins, which only feature a BH3 motif and includes Bad, Bid, Bik, Bim, Bmf, Hrk, Noxa, and Puma [8]. The BH3-only proteins modulate apoptosis by neutralizing the activity of prosurvival $\mathrm{Bcl}-2$ through binding a surface groove [9]. After activation, Bak and Bax oligomerize to perforate the outer mitochondrial membrane leading to inner membrane herniation [10] and subsequent release of cytochrome $c$, that triggers the formation of the apoptosome and activation of downstream caspases that dismantle the cell [11].

A number of large DNA viruses encode functional, sequence and structural homologs of Bcl-2 that promote infected host cell survival and viral proliferation [12]. Viral Bcl-2 homologs have been identified in herpesviridae, include those from Epstein Barr virus BHRF1 [13, 14] and Kaposi sarcoma virus KsBcl-2 [15-17]. Other major virus families that contain members encoding for pro-survival Bcl-2 proteins include the asfarviridae with 
African swine fever virus encoded A179L [18-20], and grouper iridovirus encoded GIV66 $[21,22]$ from the iridoviridae. However, the largest number of $\mathrm{Bcl}-2$ homologs are found in poxviridae [12] such as vaccinia and variola virus F1L [23-25] and myxomavirus M11L [2628]. Whilst structural studies have shown [18, 21, 24, 29-32] these virus encoded Bcl-2homologs that adopt a Bcl-2 fold, there is substantial diversity with regards to which proapoptotic host Bcl-2 proteins they bind. For example, vaccinia virus F1L binds Bim, Bak and Bax only [33], whereas sheeppoxvirus SPPV14 binds Bid, Bim, Bmf, Hrk, Puma, Bak and Bax [34], and African swine fever virus A179L binds all major pro-apoptotic Bcl-2 proteins [18]. The diversity observed amongst the proapoptotic ligand binding profiles for virus encoded prosurvival Bcl-2 extends to the mechanisms of action too, for example, myxomavirus M11L primarily acts by sequestering Bak and Bax [28], whereas vaccinia virus F1L neutralizes host cell death by sequestering Bim during viral infections [23].

Tanapoxvirus encoded TANV16L is a putative homolog of deerpoxvirus DPV022 [4] (Figure 1), with which it shares $32 \%$ sequence identity. In order to understand the putative apoptosis regulatory function of TANV16L we examined its ability to bind to peptides of host proapoptotic Bcl-2 proteins, and determined crystal structures of TANV16L bound to its interactors. We now show that TANV16L is a highly flexible Bcl-2 fold protein that is able to bind to $\mathrm{BH} 3$ motif peptides of host proapoptotic $\mathrm{Bcl}-2$ proteins with high affinity both as a monomeric and domain-swapped dimeric form. These findings provide a mechanistic basis for tanapox mediated inhibition of apoptosis, and highlight the substantial structural flexibility in the Bcl-2 fold that allows multiple oligomeric topologies to engage proapoptotic interactors using the canonical ligand binding groove.

\section{Results}


In order to reveal the function for TANV16L, we recombinantly expressed and purified TANV16L lacking the C-terminal 23 residues and examined its ability to bind to peptides spanning the BH3 motif of all proapoptotic human Bcl-2 proteins using isothermal titration calorimetry (ITC). TANV16L bound to a number of BH3 motif peptides with high affinity, including those from the BH3-only proteins Bim, Bid, Hrk and Puma as well as those from the multimotif executor proteins Bak and Bax (Figure 2, Table 1). We then utilized a yeast based heterologous expression system for studying functional interactions of TANV16L with Bak and Bax [13]. Consistent with our ITC data, we observed that TANV16L could directly counter Bak and Bax induced yeast growth arrest when these proteins were overexpressed in yeast (Figure 3).

To understand the structural basis for proapoptotic Bcl-2 binding by TANV16L we then determined the crystal structure of TANV16L bound to the human Bax, Bim and Puma BH3 motifs (Figure 4, Table 2). In the TANV16L:Bax BH3 complex, TANV16L adopts a globular Bcl-2 fold comprising $7 \alpha$-helices (Figure 4a). Similar to vaccinia and variola virus F1L and deerpoxvirus DPV022 TANV16L adopts a domain-swapped dimeric topology where the $\alpha 1$ helix from one protomer is swapped with that of a second protomer in the complex, taking up the space vacated by the matching $\alpha 1$ helix (Figures 4a, c). Superimposition of one chain of the TANV16L from the domain-swapped dimer TANV16L:Bax BH3 complex with the equivalent chain from the domain-swapped dimer VACV F1L from F1L:Bak BH3 [23] and the domain-swapped dimer DPV022 from DPV022:Bax BH3 [29] (Figures 4c, g) yields an rmsd of $2.3 \AA$ (superimposed over $122 \mathrm{C} \alpha$ atoms) and 2.1 $\AA$ (superimposed over $131 \mathrm{C} \alpha$ atoms), respectively, whereas superimposition of the entire domain-swapped dimer of TANV16L yields rmsd values of 2.2 and $2.7 \AA$, respectively. The position of the TANV16L $\alpha 1$ within the domain-swapped dimer is identical to VACV F1L and DPV022 (Figure 4f). Similarly, TANV16L in the TANV16L:Bim BH3 
complex adopts a domain swapped dimeric configuration that is identical to the TANV16L:Bax BH3 complex (Figure 4b).

Unexpectedly, TANV16L in the TANV16L: Puma BH3 complex adopts a monomeric Bcl-2 fold, where the $\alpha 1$ helix is folded back into the side of the globular Bcl-2 fold (Figure 4d). A DALI analysis [35] indicated that the closest homolog in the PDB is myxomavirus M11L (Figure 4e, PDB ID 2JBX [28]) with an rmsd of $2.1 \AA$ (over $111 \mathrm{C} \alpha$ ), whereas the closest mammalian Bcl-2 structure is human Mcl-1 (PDB ID 5FC4 [36]) with an rmsd of 2.3 $\AA$ (over $126 \mathrm{C} \alpha$ ) (Figure 4h). In the crystal structure of TPV16L:Puma BH3, one heterodimer contacts a neighbouring one via an interface formed by helices $\alpha 1$ and $\alpha 2$ from one chain and $\alpha 7$ as well as Puma BH3 from a neighbouring chain (Figure 5d). PISA (protein interfaces, surface and assembly) analysis of this interface yields a complexation significance score of 0 , which suggests it is a crystallographic dimer and not a functionally relevant interface.

TANV16L utilized the canonical Bcl-2 ligand binding groove formed by $\alpha 2-\alpha 5$ to engage BH3 motif ligands (Figure 5). In the TANV16L:Bax BH3 complex (Figure 5a), Bax residues L157, L161, I164 and L168 protrude into the four hydrophobic pockets of TANV16L. In addition, ionic interactions are observed between TANV16L R90 guanidium group and Bax D166 carboxyl as well as TANV16L R90 guanidium group and Bax D169 carboxyl group, with a further two hydrogen bonds between the TANV16L S84 hydroxyl group and the Bax S158 hydroxyl group as well as TANV16L S92 hydroxyl group and the main chain amide group of Bax G165 (Figure 5a).

In the TANV16L:Bim BH3 complex (Figure 5b), Bim residues I157, L161, I164 and F168 are used to engage the four hydrophobic pockets in TANV16L. Furthermore, there is one ionic interaction between TANV16L R90 guanidium group and Bim D166 carboxyl group and a hydrogen bond between TANV16L N87 amide and Bim R162 guanidium group. In the TANV16L: Puma BH3 complex (Figure 5c), Puma utilizes the four hydrophobic 
residues I136, L140, M143 and L147 to engage the four hydrophobic pockets in TANV16L. These hydrophobic interactions are supplemented by ionic interactions between TANV16L R90 guanidium group and Puma D145 carboxyl group as well as TANV16L K52 ammonium group and Puma D146 carboxyl group. Furthermore, two hydrogen bonds are found between TANV16L Y53 hydroxyl and Puma D146 carboxyl group, and between the TANV16L N56 sidechain amide and Puma Q139 sidechain carbonyl groups. Superimposition of monomeric TANV16L from the complex with Puma BH3 with one of the chains from the domainswapped dimeric form of TANV16L from the Bax BH3 complex yields an rmsd of $1.2 \AA$ over $\alpha 2-7$ (117 $\mathrm{C} \alpha$ atoms), indicating that despite the topology change from monomer to domain-swapped dimer the regions of TANV16L not involved in the domain swap remain near identical.

Since we observed TANV16L in both a monomeric and domain-swapped dimeric topology, we subjected TANV16L and some of its complexes with BH3 motif peptides to analytical ultracentrifugation (AUC). AUC was performed on TANV16L alone as well as on TANV16L bound to Bim, Bax and Puma BH3 (Figure 6). TANV16L alone revealed a mixture of monomeric and dimeric protein as well as a small amount of tetramers at concentrations ranging from $0.2-0.8 \mathrm{mg} / \mathrm{mL}$, with a ratio of monomer:dimer of $\sim 3.5: 1$. Similarly, complexes of TANV16L with Bim, Bax and Puma BH3 at $0.2 \mathrm{mg} / \mathrm{mL}$ also revealed a mixture of heterodimers and heterotetramers, with the ratio of TANV16L:Bim BH3 heterodimers vs heterotetramers being 4:1, with TANV16L: Bax and Puma complexes displaying comparable ratios of $\sim 3.5: 1$, respectively, closely matching the ratio observed for TANV16L alone (Figure 6).

To validate the crystal structures of TANV16L bound to Bim, Bax and Puma BH3 we performed structure-guided mutagenesis (Figure 5e and analysed the mutants for their ability to bind to proapoptotic BH3 motif peptides (Table 1). Mutation of the conserved R90 in 
TANV16L substantially impacts on its ability to bind BH3 motif peptides, with 10-80 fold reduction in affinities for Bim, Bad, Bid, Bik as well as Bak and Bax BH3 binding, whereas binding to Hrk and Puma BH3 is only reduced 2-fold (Figure 7). In contrast, whilst mutation of K52 to Ala also led to a 2-4 fold reduction in binding affinities for many interactors, binding to Bid BH3 was largely unaffected. Binding to Bad and Bmf BH3 was reduced by 27 and 20 fold, respectively (Figure 8).

\section{Discussion}

Altruistic death of an infected cell is a potent mechanism to restrict viral infections. Viruses have evolved numerous strategies to prevent premature host cell death to establish productive infections [12]. Tanapoxvirus encodes TANV16L, a putative Bcl-2 homolog, and we now show that TANV16L adopts both a classical monomeric form as well as a domain-swapped dimer. Dimeric TANV16L is able to bind both $\mathrm{BH} 3$-only proteins as well as the $\mathrm{BH} 3$ regions of Bak and Bax. TANV16L harbours a broad proapoptotic BH3 ligand binding profile when compared to other poxvirus encoded domain-swapped pro-survival Bcl-2 proteins. The poxvirus encoded pro-survival Bcl-2 homologs VACV F1L [33], VARV F1L [24] and deerpoxvirus DPV022 [29] all have similar dimeric topologies to TANV16L dimer but feature more restricted interaction and affinity profiles. VACV F1L [33] and DPV022 [29] only bind to Bim, Bak and Bak whereas VARV F1L binds Bid, Bak and Bax [24]. In all three cases these interactions are characterized by lower affinities, in particular for Bak and Bax which bind with only micromolar affinities to VACV F1L, DPV022 F1L and DPV022. In contrast, TANV16L displays much tighter affinities including $38 \mathrm{nM}$ for Bak and $70 \mathrm{nM}$ for Bax BH3 (Table 1). Intriguingly, TANV16L is able to adopt both monomeric and domainswapped dimer topologies, however the domain swap does to not impact significantly on the configuration of the canonical ligand binding groove. Superimposition of monomeric and 
dimeric TANV16L reveals there are virtually no differences in the respective ligand binding grooves. However, no thermodynamic analysis has been performed to examine such effects on ligand binding. When performing AUC analysis, we observed a small amount of a homotetrameric species of TANV16L in addition to monomeric and dimeric TAV16L, However, no homotetrameric structures of Bcl-2 proteins have been determined to date. Coupled with the identification of other unexpected avenues for multimerization such as a groove-in-groove dimer as shown recently for GIV66 [21] we are unable to speculate as to what a potential homotetrameric species of TAV16L may look like with regards to the overall topology and multimerization route.

A comparison of the overall dimeric structures of TANV16L with other domain swapped poxviral Bcl-2 dimers reveals that dimeric TANV16L superimposes on a VACV F1L dimer with an rmsd of $2.2 \AA$ (over $266 \mathrm{C} \alpha$ atoms) and on dimeric DPV022 with $2.7 \AA$ (over $274 \mathrm{C} \alpha$ atoms). This high level of similarity is achieved despite low overall sequence identity (8\% between TANV16L and VACV F1L and $31 \%$ between TANV16L and DPV022). A detailed comparison of the interactions formed by TANV16L and DPV022 when bound to Bax reveals that the hallmark interaction between the conserved Asp from Bax BH3 with an Arg from TANV16L or DPV022 BH1 is preserved, as are hydrogen bonds between Bax Ser158 and Asp169 with TANV16L S84 or DPV022 E80. As expected, loss of the hallmark ionic interaction severely impacts TANV16L ability to bind to pro-apoptotic Bcl-2 interactors, with a TANV16L R90A mutation displaying up to 80 fold reduction in affinity (Table 1), as previously observed for mammalian prosurvival Bcl-2 [37]. Unlike in the DPV022 complex with Bax [29], the bulk of the BH3 peptides are engaged in the TANV16L ligand binding groove resulting in buried surface areas of 2343-3142 $\AA^{2}$ for the complexes with Bax, Bim and Puma, whereas in DPV022:Bax BH3 only 4 helical turns are engaged that bury $2117 \AA^{2}$, which may contribute to the more modest affinity of the 
interaction. The more extensive engagement of the TANV16L binding groove with a BH3 peptide thus provides a possible rational for the substantially tighter binding observed compared with DPV022.

Virus encoded Bcl-2 proteins are not limited to domain-swapping for dimer formation (Figure 9). Vaccinia virus has been shown to encode for a suite of Bcl-2 fold proteins that modulate NF- $\kappa \mathrm{B}$ signalling, with several of them adopting different dimeric topologies. N1[38], B14 and A52 [39] utilize an interface formed by helices $\alpha 1$ and $\alpha 6$, whereas A46 forms a dimer via an $\alpha 4$ and $\alpha 6$ interface [40]. In contrast, grouper iridovirus encoded GIV66 forms dimers that occlude the canonical ligand binding groove, with binding of $\mathrm{BH} 3$ motif peptides dissociating the dimers [21]. Domain-swapping is not limited to virus-encoded Bcl-2 proteins, and is also observed in mammalian Bcl-2 proteins. Bcl- $\mathrm{x}_{\mathrm{L}}$ has been shown to adopt domain-swapped topologies featuring either $\alpha 5-\alpha 8$ or $\alpha 1$ swaps. However, these swaps were induced by exposure to extreme $\mathrm{pH}$ [41] or temperature environments [42] or by truncation of the loop connecting $\alpha 1$ and $\alpha 2$ [43], respectively. In contrast, recombinantly expressed Bcl-w lacking its C-terminal tail adopts both a monomeric state as well as a domain swapped dimeric state where $\alpha 3-\alpha 4$ are swapped $[44,45]$. Such a swap impacts the canonical ligand binding groove, and leads to differential binding affinities between monomeric and dimeric Bcl-w [45]. Domain swapping has also been shown for human proapoptotic Bak [46] and Bax [47], where the formation of an extended single helix comprising helices $\alpha 5$ and $\alpha 6$ leads to a core/latch configuration, where a core domain formed by $\alpha 1-4$ partners the latch domain formed by $\alpha 6-\alpha 8$ from a second protomer. In contrast, catfish Bax features a domain swapped $\alpha 9$ helix [48]. This significant number of topological variances across dimeric Bcl-2 proteins underscores the inherent flexibility in this fold, and potentially enables additional layers of functionality to modulate function in addition to direct interactions. 
In summary, we report the biochemical and structural analysis of tanapoxvirus 16L, which revealed a broad high affinity binding profile for mammalian pro-apoptotic Bcl-2 proteins. Furthermore, our crystal structures of TANV16L bound to Bax and Puma BH3 indicate that TANV16L displays substantial structural plasticity, being able to adopt both a classical monomeric Bcl-2 fold as well as a domain-swapped dimeric Bcl-2 fold. Overall, our findings provide a mechanistic platform for dissecting the role of $16 \mathrm{~L}$ for tanapoxvirus replication and infectivity.

\section{Materials and methods}

\section{Protein expression and purification}

Synthetic cDNA encoding for codon optimized wildtype TANV16L (Uniprot Accession number Q9DHU6) as well as two mutants TANV16L (K52A and R90A) lacking 23 Cterminal residues were cloned into the bacterial expression vector pGex-6p-1 (Genscript). Recombinant TANV16L was expressed in C41(DE3) cells in 2YT medium supplemented with $1 \mathrm{mg} / \mathrm{ml}$ ampicillin at $37^{\circ} \mathrm{C}$ in a shaking incubator until an $\mathrm{OD}_{600}$ of 0.6 was reached. The protein expression was induced by adding isopropyl $\beta$-D-1-thiogalactopyranoside (IPTG) to final concentration of $0.75 \mathrm{mM}$ for 18 hours at $20^{\circ} \mathrm{C}$. Bacterial cells were harvested by centrifugation at $5000 \mathrm{rpm}$ (JLA 9.1000 rotor, Beckman Coulter Avanti J-E) for 20 min and re-suspended in $100 \mathrm{ml}$ lysis buffer A (50 mM Tris $\mathrm{pH} 8.0,300 \mathrm{mM} \mathrm{NaCl}$ and $10 \mathrm{mM}$ DTT (dithiothreitol). The cells were homogenized using an Avestin EmulsiFlex homogenizer and lysed using sonication (programme 7, Fisher Scientific ${ }^{\mathrm{TM}}$ Model 705 Sonic Dismembrator) and the resultant lysate was transferred into SS34 tubes for further centrifugation at 18,000 rpm (JA-25.50 rotor, Beckman Coulter Avanti J-E) for 30 min. The supernatant was loaded onto $5 \mathrm{~mL}$ of glutathione sepharose 4B (GE Healthcare) equilibrated with buffer A. After sample application, the column was washed with $150 \mathrm{ml}$ of buffer A and protein on-column 
cleavage was achieved by adding HRV 3C protease overnight at $4^{\circ} \mathrm{C}$. The cleaved protein was eluted using buffer A, with the remaining protein being concentrated using a centrifugal concentrator with $3 \mathrm{kDa}$ molecular weight cut-off (Amicon® Ultra 15) to a final volume of 2 ml. Concentrated TANV16L was subjected to size-exclusion chromatography using a Superdex S200 increase 10/300 column mounted on an ÄKTA Pure system (GE Healthcare) equilibrated in $25 \mathrm{mM}$ HEPES $\mathrm{pH} 7.5,150 \mathrm{mM} \mathrm{NaCl}$ and $5 \mathrm{mM}$ TCEP (Tris(2carboxyethyl)phosphine hydrochloride), and fractions analysed using SDS-PAGE. The final sample purity was estimated to be greater than $95 \%$ based on SDS-PAGE analysis. Appropriate fractions were pooled and concentrated using a centrifugal concentrator with 3 $\mathrm{kDa}$ molecular weight cut-off (Amicon ${ }^{\circledR}$ Ultra 15 ) to final concentration of $5.4 \mathrm{mg} / \mathrm{ml}$.

\section{Analytical ultracentrifugation}

Sedimentation velocity experiments were performed in a Beckman Coulter XL-A analytical ultracentrifuge as described previously [49-52]. Briefly, double sector quartz cells were loaded with $400 \square \mu l$ of buffer (25 mM HEPES pH 7.5, $150 \mathrm{mM} \mathrm{NaCl,} \mathrm{5mM} \mathrm{TCEP)} \mathrm{and}$ $380 \square \mu l$ of sample (solubilized in buffer). For the runs with apo protein, initial concentrations of $0.2 \mathrm{mg} / \mathrm{ml}, 0.4 \mathrm{mg} / \mathrm{ml}$ and $0.8 \mathrm{mg} / \mathrm{ml}$ were employed. For the runs with the complexes, the protein and peptide concentrations were kept at $0.2 \mathrm{mg} / \mathrm{ml}$. The cells were loaded into an An50-Ti rotor and the experiments conducted at $25^{\circ} \mathrm{C}$. Initial scans were carried out at $3,000 \square \mathrm{rpm}$ to determine the optimal wavelength and radial positions. Final scans were performed at $40,000 \square \mathrm{rpm}$ and data were collected continuously at $230 \square \mathrm{nm}$ using a step size of $0.003 \square \mathrm{cm}$ without averaging. Solvent density, solvent viscosity and estimates of the partial specific volume of apo-TANV16L, TANV16L:Bim, TANV16L:Puma and TANV16L:Bax. at $25^{\circ} \mathrm{C}$ were calculated using SEDNTERP [53]. Data were fitted using the 
SEDFIT software (www.analyticalultracentrifugation.com) to a continuous size-distribution model [54-56].

\section{Measurement of dissociation constants}

Binding affinities were measured using a MicroCal iTC200 system (GE Healthcare) at $25^{\circ} \mathrm{C}$ using wild type TANV16L as well as two mutants TANV16L K52A and R90A in $25 \mathrm{mM}$ HEPES pH 7.5, $150 \mathrm{mM} \mathrm{NaCl}, 5 \mathrm{mM}$ TCEP. Measurements were performed at a range of different concentrations for $\mathrm{BH} 3$ motif peptide and TANV16L proteins, which are summarized below in Table 3. All affinity measurements were performed in triplicate. Protein concentrations were measured using a Nanodrop UV spectrophotometer (Thermo Scientific) at a wavelength of $280 \mathrm{~nm}$. Peptide concentrations were calculated based on the dry peptide weight after synthesis. The BH3-motif peptides used were commercially synthesized and were purified to a final purity of $95 \%$ (GenScript) and based on the human sequences as previously described [57].

Table 3: Summary of protein and ligand concentrations used in ITC measurements

\begin{tabular}{|l|c|c|}
\hline \multicolumn{1}{|c|}{ Interaction } & $\begin{array}{c}\text { Protein concentration } \\
(\mu \mathbf{m})\end{array}$ & $\begin{array}{c}\text { BH3 motif peptide } \\
\text { concentration }(\boldsymbol{\mu m})\end{array}$ \\
\hline TANV16L:Bak BH3 & 60 & 600 \\
\hline TANV16L:Bax BH3 & 60 & 600 \\
\hline TANV16L:Bok BH3 & 60 & 600 \\
\hline TANV16L:Bad BH3 & 60 & 550 \\
\hline TANV16L:Bid BH3 & 60 & 600 \\
\hline TANV16L:Bik BH3 & 60 & 750 \\
\hline TANV16L:Bim BH3 & 60 & 600 \\
\hline TANV16L:Bmf BH3 & 60 & 800 \\
\hline TANV16L:Hrk BH3 & 60 & 600 \\
\hline TANV16L:Noxa BH3 & 60 & 600 \\
\hline TANV16L:Puma BH3 & 60 & 700 \\
\hline TANV16L_R90A:Bak BH3 & 60 & 600 \\
\hline TANV16L_R90A:Bax BH3 & 60 & 800 \\
\hline TANV16L_R90A:Bok BH3 & 60 & 600 \\
\hline
\end{tabular}




\begin{tabular}{|l|l|c|}
\hline TANV16L_R90A:Bad BH3 & 60 & 950 \\
\hline TANV16L_R90A:Bid BH3 & 60 & 900 \\
\hline TANV16L_R90A:Bik BH3 & 60 & 700 \\
\hline TANV16L_R90A:Bim BH3 & 60 & 600 \\
\hline TANV16L_R90A:Bmf BH3 & 60 & 900 \\
\hline TANV16L_R90A:Hrk BH3 & 65 & 900 \\
\hline TANV16L_R90A:Noxa BH3 & 60 & 600 \\
\hline TANV16L_R90A:Puma BH3 & 60 & 600 \\
\hline TANV16L_K52A:Bak BH3 & 60 & 550 \\
\hline TANV16L_K52A:Bax BH3 & 60 & 550 \\
\hline TANV16L_K52A:Bok BH3 & 60 & 600 \\
\hline TANV16L_K52A:Bad BH3 & 60 & 1000 \\
\hline TANV16L_K52A:Bid BH3 & 60 & 800 \\
\hline TANV16L_K52A:Bik BH3 & 60 & 650 \\
\hline TANV16L_K52A:Bim BH3 & 60 & 600 \\
\hline TANV16L_K52A:Bmf BH3 & 60 & 850 \\
\hline TANV16L_K52A:Hrk BH3 & 65 & 600 \\
\hline TANV16L_K52A:Noxa BH3 & 60 & 600 \\
\hline TANV16L_K52A:Puma BH3 & 60 & 600 \\
\hline
\end{tabular}

\section{Crystallization and structure determination}

Crystals for TANV16L: Bax BH3, TANV16L: Puma BH3 or TANV16L: Bim BH3 complexes were obtained by mixing TANV16L with human Bax BH3 28-mer or Puma BH3 26-mer peptide into 1:1.25 molar ratio as described previously [58] and concentrated using a centrifugal concentrator with $3 \mathrm{kDa}$ molecular weight cut-off (Amicon ® Ultra 0.5) to 5 $\mathrm{mg} / \mathrm{ml}$ and concentrated protein was immediately used for crystallization trials. Initial high throughput sparse matrix screening was performed using 96 well sitting drop trays (swissic, Neuheim, Switzerland) using $200 \mathrm{~nL}$ of protein mixed with $200 \mathrm{~nL}$ of reservoir solution.

TANV16L: Bax BH3 crystals were grown by the sitting drop vapour diffusion method at $20^{\circ} \mathrm{C}$ in $1.0 \mathrm{M} \mathrm{LiCl}, 0.1 \mathrm{M}$ Citrate $\mathrm{pH} 4.0,20 \% \mathrm{~W} / \mathrm{V}$ PEG 6000. The crystals were flash cooled at $-173^{\circ} \mathrm{C}$ in mother liquor supplemented with $20 \%$ ethylene glycol. Diffraction data were collected at the Australian Synchrotron MX2 beamline using an Eiger detector with an oscillation range $0.1^{\circ}$ per frame with a wavelength of $0.9537 \AA$, integrated using XDS [59] and scaled using AIMLESS [60]. Molecular replacement was carried out 
using PHASER [61] with the previously solved structure of DPV022 (PDB ID: 4UF1 [29]) as a search model. TANV16L: Bax BH3 crystals contained one molecule of TANV16L and one Bax BH3 peptide in the asymmetric unit, with $46.3 \%$ solvent content and final TFZ and LLG values of 8.0 and 52.79 respectively. The final model of TANV16L: Bax BH3 was built manually over several cycles using Coot [62] and refined using PHENIX [63].

TANV16L: Puma BH3 crystals were grown as the TANV16L: Bax BH3 crystals and were obtained in $0.1 \mathrm{M}$ Potassium thiocyanate, 30\% PEG 2000MME. The crystals were flash cooled at $-173^{\circ} \mathrm{C}$ in mother liquor. Diffraction data collection, integration and scaling were performed as described above. The molecular replacement was carried out using PHASER with the previously solved structure of TANV16L: Bax BH3 as a search model. TANV16L: Puma BH3 crystals contain one molecule of TANV16L and one Puma BH3 peptide, with 46.3\% solvent content and final TFZ and LLG values of 13.2 and 133.15 respectively. The final model of TANV16L: Puma BH3 was built manually over several cycles using Coot and refined using PHENIX.

TANV16L: Bim BH3 crystals were grown similar to other two complexes as above and in $0.1 \mathrm{M}$ MIB buffer $\mathrm{pH} 8.0,25 \%$ PEG 1500. The crystals were flash cooled at $-173^{\circ} \mathrm{C}$ in mother liquor. Diffraction data collection, integration and scaling were performed as described above. Molecular replacement was carried out using PHASER with the previously solved structure of TANV16L: Bax BH3 as a search model. TANV16L: Bim BH3 crystals contain one molecule of TANV16L and one Bim BH3 peptide, with 44.01\% solvent content and final TFZ and LLG values of 15.8 and 208.64 respectively. The final model of TANV16L: Bim BH3 was built manually and refined as described above. Coordinate files have been deposited in the Protein Data Bank under the accession codes 6TPQ, 6TQQ and 6TRR. All images were generated using the PyMOL Molecular Graphics System, Version 1.8 Schrödinger, LLC. All software was accessed using the SBGrid suite [64]. All raw 
diffraction images were deposited on the SBGrid Data Bank [65] using their PDB accession code 6TPQ, 6TQQ and 6TRR.

\section{Sequence alignment and interface analysis}

Sequence alignments were performed using MUSCLE [66] (https://www.ebi.ac.uk/Tools/msa/muscle/) with the default settings, and sequence identities were calculated based on the total number of conserved residues in TANV16L against the full sequence. Protein interfaces were analysed using PISA [67].

\section{Yeast colony assays}

Saccharomyces cerevisiae W303 $\alpha$ cells were co-transformed with pGALL(TRP) vector only, pGALL(TRP)-Bcl-x $x_{L}$, or pGALL(TRP)-TANV16L and pGALL(Leu)-Bak or pGALL(Leu)Bax. pGALL(TRP) and pGALL(Leu) places genes under the control of a galactose inducible promoter [68]. Cells were subsequently spotted as a 5-fold serial dilution series onto medium supplemented with $2 \%$ w/v galactose (inducing, "ON") to induces protein expression, or $2 \%$ w/v glucose (repressing, "OFF”), which prevents protein expression, as previously described [69]. Plates were incubated for $48 \mathrm{~h}$ at $30^{\circ} \mathrm{C}$ and then photographed.

\section{References:}

1. Downie, A. W., Taylor-Robinson, C. H., Caunt, A. E., Nelson, G. S., Manson-Bahr, P. E. \& Matthews, T. C. (1971) Tanapox: a new disease caused by a pox virus, Br Med J. 1, 363-8. 2. Knight, J. C., Novembre, F. J., Brown, D. R., Goldsmith, C. S. \& Esposito, J. J. (1989) Studies on Tanapox virus, Virology. 172, 116-24.

3. Brunetti, C. R., Paulose-Murphy, M., Singh, R., Qin, J., Barrett, J. W., Tardivel, A., Schneider, P., Essani, K. \& McFadden, G. (2003) A secreted high-affinity inhibitor of human TNF from Tanapox virus, Proc Natl Acad Sci U S A. 100, 4831-6.

4. Nazarian, S. H., Barrett, J. W., Frace, A. M., Olsen-Rasmussen, M., Khristova, M., Shaban, M., Neering, S., Li, Y., Damon, I. K., Esposito, J. J., Essani, K. \& McFadden, G. (2007) Comparative genetic analysis of genomic DNA sequences of two human isolates of Tanapox virus, Virus Res. 129, 11-25.

5. Kvansakul, M. \& Hinds, M. G. (2015) The Bcl-2 family: structures, interactions and targets for drug discovery, Apoptosis. 20, 136-50. 
6. Banjara, S., Suraweera, C. D., Hinds, M. G. \& Kvansakul, M. (2020) The Bcl-2 Family: Ancient Origins, Conserved Structures, and Divergent Mechanisms., Biomolecules. 10, 128. 7. Kvansakul, M. \& Hinds, M. G. (2013) Structural biology of the Bcl-2 family and its mimicry by viral proteins, Cell Death Dis. 4, e909.

8. Kvansakul, M. \& Hinds, M. G. (2014) The structural biology of BH3-only proteins, Methods Enzymol. 544, 49-74.

9. Shamas-Din, A., Kale, J., Leber, B. \& Andrews, D. W. (2013) Mechanisms of action of bcl-2 family proteins, Cold Spring Harb Perspect Biol. 5, a008714.

10. McArthur, K., Whitehead, L. W., Heddleston, J. M., Li, L., Padman, B. S., Oorschot, V., Geoghegan, N. D., Chappaz, S., Davidson, S., San Chin, H., Lane, R. M., Dramicanin, M., Saunders, T. L., Sugiana, C., Lessene, R., Osellame, L. D., Chew, T. L., Dewson, G., Lazarou, M., Ramm, G., Lessene, G., Ryan, M. T., Rogers, K. L., van Delft, M. F. \& Kile, B. T. (2018) BAK/BAX macropores facilitate mitochondrial herniation and mtDNA efflux during apoptosis, Science. 359.

11. Tait, S. W. \& Green, D. R. (2010) Mitochondria and cell death: outer membrane permeabilization and beyond, Nat Rev Mol Cell Biol. 11, 621-32.

12. Kvansakul, M., Caria, S. \& Hinds, M. G. (2017) The Bcl-2 Family in Host-Virus Interactions, Viruses. 9, 290.

13. Kvansakul, M., Wei, A. H., Fletcher, J. I., Willis, S. N., Chen, L., Roberts, A. W., Huang, D. C. \& Colman, P. M. (2010) Structural basis for apoptosis inhibition by EpsteinBarr virus BHRF1, PLoS Pathog. 6, e1001236.

14. Henderson, S., Huen, D., Rowe, M., Dawson, C., Johnson, G. \& Rickinson, A. (1993) Epstein-Barr virus-coded BHRF1 protein, a viral homologue of Bcl-2, protects human B cells from programmed cell death, Proc Natl Acad Sci U S A. 90, 8479-83.

15. Huang, Q., Petros, A. M., Virgin, H. W., Fesik, S. W. \& Olejniczak, E. T. (2002)

Solution structure of a Bcl-2 homolog from Kaposi sarcoma virus, Proc Natl Acad Sci U S A. 99, 3428-33.

16. Sarid, R., Sato, T., Bohenzky, R. A., Russo, J. J. \& Chang, Y. (1997) Kaposi's sarcomaassociated herpesvirus encodes a functional bcl-2 homologue, Nat Med. 3, 293-8.

17. Cheng, E. H., Nicholas, J., Bellows, D. S., Hayward, G. S., Guo, H. G., Reitz, M. S. \& Hardwick, J. M. (1997) A Bcl-2 homolog encoded by Kaposi sarcoma-associated virus, human herpesvirus 8, inhibits apoptosis but does not heterodimerize with Bax or Bak, Proc Natl Acad Sci U S A. 94, 690-4.

18. Banjara, S., Caria, S., Dixon, L. K., Hinds, M. G. \& Kvansakul, M. (2017) Structural Insight into African Swine Fever Virus A179L-Mediated Inhibition of Apoptosis, J Virol. 91, e02228-16.

19. Brun, A., Rivas, C., Esteban, M., Escribano, J. M. \& Alonso, C. (1996) African swine fever virus gene A179L, a viral homologue of bcl-2, protects cells from programmed cell death, Virology. 225, 227-30.

20. Banjara, S., Shimmon, G. L., Dixon, L. K., Netherton, C. L., Hinds, M. G. \& Kvansakul, M. (2019) Crystal Structure of African Swine Fever Virus A179L with the Autophagy Regulator Beclin, Viruses. 11, 789.

21. Banjara, S., Mao, J., Ryan, T. M., Caria, S. \& Kvansakul, M. (2018) Grouper iridovirus GIV66 is a Bcl-2 protein that inhibits apoptosis by exclusively sequestering Bim, J Biol Chem. 293, 5464-5477.

22. Lin, P. W., Huang, Y. J., John, J. A., Chang, Y. N., Yuan, C. H., Chen, W. Y., Yeh, C. H., Shen, S. T., Lin, F. P., Tsui, W. H. \& Chang, C. Y. (2008) Iridovirus Bcl-2 protein inhibits apoptosis in the early stage of viral infection, Apoptosis. 13, 165-76. 
23. Campbell, S., Thibault, J., Mehta, N., Colman, P. M., Barry, M. \& Kvansakul, M. (2014) Structural insight into BH3 domain binding of vaccinia virus antiapoptotic F1L, J Virol. 88, 8667-77.

24. Marshall, B., Puthalakath, H., Caria, S., Chugh, S., Doerflinger, M., Colman, P. M. \& Kvansakul, M. (2015) Variola virus F1L is a Bcl-2-like protein that unlike its vaccinia virus counterpart inhibits apoptosis independent of Bim, Cell Death Dis. 6, e1680.

25. Wasilenko, S. T., Stewart, T. L., Meyers, A. F. \& Barry, M. (2003) Vaccinia virus encodes a previously uncharacterized mitochondrial-associated inhibitor of apoptosis, Proc Natl Acad Sci U S A. 100, 14345-50.

26. Opgenorth, A., Graham, K., Nation, N., Strayer, D. \& McFadden, G. (1992) Deletion analysis of two tandemly arranged virulence genes in myxoma virus, M11L and myxoma growth factor, $J$ Virol. 66, 4720-31.

27. Douglas, A. E., Corbett, K. D., Berger, J. M., McFadden, G. \& Handel, T. M. (2007) Structure of M11L: A myxoma virus structural homolog of the apoptosis inhibitor, Bcl-2, Protein Sci. 16, 695-703.

28. Kvansakul, M., van Delft, M. F., Lee, E. F., Gulbis, J. M., Fairlie, W. D., Huang, D. C. \& Colman, P. M. (2007) A structural viral mimic of prosurvival Bcl-2: a pivotal role for sequestering proapoptotic Bax and Bak, Mol Cell. 25, 933-42.

29. Burton, D. R., Caria, S., Marshall, B., Barry, M. \& Kvansakul, M. (2015) Structural basis of Deerpox virus-mediated inhibition of apoptosis, Acta Crystallogr D Biol Crystallogr. 71, 1593-603.

30. Anasir, M. I., Baxter, A. A., Poon, I. K. H., Hulett, M. D. \& Kvansakul, M. (2017) Structural and Functional Insight into Canarypox Virus CNP058 Mediated Regulation of Apoptosis, Viruses. 9, 305.

31. Anasir, M. I., Caria, S., Skinner, M. A. \& Kvansakul, M. (2017) Structural basis of apoptosis inhibition by the fowlpox virus protein FPV039, J Biol Chem. 292, 9010-9021. 32. Suraweera, C. D., Burton, D. R., Hinds, M. G. \& Kvansakul, M. (2020) Crystal structures of the sheeppoxvirus encoded inhibitor of apoptosis SPPV14 bound to Hrk and Bax BH3 peptides, BioRxiv.

33. Kvansakul, M., Yang, H., Fairlie, W. D., Czabotar, P. E., Fischer, S. F., Perugini, M. A., Huang, D. C. \& Colman, P. M. (2008) Vaccinia virus anti-apoptotic F1L is a novel Bcl-2-like domain-swapped dimer that binds a highly selective subset of $\mathrm{BH} 3$-containing death ligands, Cell Death Differ. 15, 1564-71.

34. Okamoto, T., Campbell, S., Mehta, N., Thibault, J., Colman, P. M., Barry, M., Huang, D. C. \& Kvansakul, M. (2012) Sheeppox virus SPPV14 encodes a Bcl-2-like cell death inhibitor that counters a distinct set of mammalian proapoptotic proteins, J Virol. 86, 11501-11. 35. Holm, L. \& Rosenstrom, P. (2010) Dali server: conservation mapping in 3D, Nucleic Acids Res. 38, W545-9.

36. Pelz, N. F., Bian, Z., Zhao, B., Shaw, S., Tarr, J. C., Belmar, J., Gregg, C., Camper, D. V., Goodwin, C. M., Arnold, A. L., Sensintaffar, J. L., Friberg, A., Rossanese, O. W., Lee, T., Olejniczak, E. T. \& Fesik, S. W. (2016) Discovery of 2-Indole-acylsulfonamide Myeloid Cell Leukemia 1 (Mcl-1) Inhibitors Using Fragment-Based Methods, J Med Chem. 59, 205466.

37. Sattler, M., Liang, H., Nettesheim, D., Meadows, R. P., Harlan, J. E., Eberstadt, M., Yoon, H. S., Shuker, S. B., Chang, B. S., Minn, A. J., Thompson, C. B. \& Fesik, S. W. (1997) Structure of Bcl-xL-Bak peptide complex: recognition between regulators of apoptosis, Science. 275, 983-6.

38. Cooray, S., Bahar, M. W., Abrescia, N. G., McVey, C. E., Bartlett, N. W., Chen, R. A., Stuart, D. I., Grimes, J. M. \& Smith, G. L. (2007) Functional and structural studies of the 
vaccinia virus virulence factor N1 reveal a Bcl-2-like anti-apoptotic protein, J Gen Virol. 88, 1656-66.

39. Graham, S. C., Bahar, M. W., Cooray, S., Chen, R. A., Whalen, D. M., Abrescia, N. G., Alderton, D., Owens, R. J., Stuart, D. I., Smith, G. L. \& Grimes, J. M. (2008) Vaccinia virus proteins A52 and B14 Share a Bcl-2-like fold but have evolved to inhibit NF-kappaB rather than apoptosis, PLoS Pathog. 4, e1000128.

40. Fedosyuk, S., Grishkovskaya, I., de Almeida Ribeiro, E., Jr. \& Skern, T. (2014)

Characterization and structure of the vaccinia virus NF-kappaB antagonist A46, J Biol Chem. 289, 3749-62.

41. O'Neill, J. W., Manion, M. K., Maguire, B. \& Hockenbery, D. M. (2006) BCL-XL dimerization by three-dimensional domain swapping, J Mol Biol. 356, 367-81.

42. Denisov, A. Y., Sprules, T., Fraser, J., Kozlov, G. \& Gehring, K. (2007) Heat-induced dimerization of BCL-xL through alpha-helix swapping, Biochemistry. 46, 734-40.

43. Oberstein, A., Jeffrey, P. D. \& Shi, Y. (2007) Crystal structure of the Bcl-XL-Beclin 1 peptide complex: Beclin 1 is a novel BH3-only protein, J Biol Chem. 282, 13123-32.

44. Hinds, M. G., Lackmann, M., Skea, G. L., Harrison, P. J., Huang, D. C. \& Day, C. L. (2003) The structure of Bcl-w reveals a role for the C-terminal residues in modulating biological activity, EMBO J. 22, 1497-507.

45. Lee, E. F., Dewson, G., Smith, B. J., Evangelista, M., Pettikiriarachchi, A., Dogovski, C., Perugini, M. A., Colman, P. M. \& Fairlie, W. D. (2011) Crystal Structure of a BCL-W Domain-Swapped Dimer: Implications for the Function of BCL-2 Family Proteins, Structure. 19, 1467-76.

46. Brouwer, J. M., Westphal, D., Dewson, G., Robin, A. Y., Uren, R. T., Bartolo, R., Thompson, G. V., Colman, P. M., Kluck, R. M. \& Czabotar, P. E. (2014) Bak core and latch domains separate during activation, and freed core domains form symmetric homodimers, Mol Cell. 55, 938-946.

47. Czabotar, P. E., Westphal, D., Dewson, G., Ma, S., Hockings, C., Fairlie, W. D., Lee, E. F., Yao, S., Robin, A. Y., Smith, B. J., Huang, D. C., Kluck, R. M., Adams, J. M. \& Colman, P. M. (2013) Bax crystal structures reveal how BH3 domains activate Bax and nucleate its oligomerization to induce apoptosis, Cell. 152, 519-31.

48. Robin, A. Y., Iyer, S., Birkinshaw, R. W., Sandow, J., Wardak, A., Luo, C. S., Shi, M., Webb, A. I., Czabotar, P. E., Kluck, R. M. \& Colman, P. M. (2018) Ensemble Properties of Bax Determine Its Function, Structure. 26, 1346-1359 e5.

49. Soares da Costa, T. P., Yap, M. Y., Perugini, M. A., Wallace, J. C., Abell, A. D., Wilce, M. C., Polyak, S. W. \& Booker, G. W. (2014) Dual roles of F123 in protein

homodimerization and inhibitor binding to biotin protein ligase from Staphylococcus aureus, Mol Microbiol. 91, 110-20.

50. Soares da Costa, T. P., Patel, M., Desbois, S., Gupta, R., Faou, P. \& Perugini, M. A. (2017) Identification of a dimeric KDG aldolase from Agrobacterium tumefaciens, Proteins. 85, 2058-2065.

51. Soares da Costa, T. P., Desbois, S., Dogovski, C., Gorman, M. A., Ketaren, N. E., Paxman, J. J., Siddiqui, T., Zammit, L. M., Abbott, B. M., Robins-Browne, R. M., Parker, M. W., Jameson, G. B., Hall, N. E., Panjikar, S. \& Perugini, M. A. (2016) Structural

Determinants Defining the Allosteric Inhibition of an Essential Antibiotic Target, Structure.

24, 1282-1291.

52. Soares da Costa, T. P., Christensen, J. B., Desbois, S., Gordon, S. E., Gupta, R., Hogan, C. J., Nelson, T. G., Downton, M. T., Gardhi, C. K., Abbott, B. M., Wagner, J., Panjikar, S. \& Perugini, M. A. (2015) Quaternary Structure Analyses of an Essential Oligomeric Enzyme, Methods Enzymol. 562, 205-23. 
53. Laue, T. M. (1992) Computer-aided interpretation of analytical sedimentation data for proteins, Analytical Ultracentrifugation in Biochemistry and Polymer Science, 90-125.

54. Schuck, P., Perugini, M. A., Gonzales, N. R., Howlett, G. J. \& Schubert, D. (2002) Sizedistribution analysis of proteins by analytical ultracentrifugation: strategies and application to model systems, Biophys J. 82, 1096-111.

55. Schuck, P. (2000) Size-distribution analysis of macromolecules by sedimentation velocity ultracentrifugation and lamm equation modeling, Biophys $J$. 78, 1606-19.

56. Perugini, M. A., Schuck, P. \& Howlett, G. J. (2002) Differences in the binding capacity of human apolipoprotein E3 and E4 to size-fractionated lipid emulsions, Eur J Biochem. 269, 5939-49.

57. Caria, S., Hinds, M. G. \& Kvansakul, M. (2017) Structural insight into an evolutionarily ancient programmed cell death regulator - the crystal structure of marine sponge BHP2 bound to LB-Bak-2, Cell Death Dis. 8, e2543.

58. Kvansakul, M. \& Czabotar, P. E. (2016) Preparing Samples for Crystallization of Bcl-2 Family Complexes, Methods Mol Biol. 1419, 213-29.

59. Kabsch, W. (2010) Xds, Acta Crystallogr D Biol Crystallogr. 66, 125-32.

60. Evans, P. (2006) Scaling and assessment of data quality, Acta Crystallogr D Biol Crystallogr. 62, 72-82.

61. McCoy, A. J. (2007) Solving structures of protein complexes by molecular replacement with Phaser, Acta Crystallogr D Biol Crystallogr. 63, 32-41.

62. Emsley, P., Lohkamp, B., Scott, W. G. \& Cowtan, K. (2010) Features and development of Coot, Acta Crystallogr D Biol Crystallogr. 66, 486-501.

63. Echols, N., Grosse-Kunstleve, R. W., Afonine, P. V., Bunkoczi, G., Chen, V. B., Headd, J. J., McCoy, A. J., Moriarty, N. W., Read, R. J., Richardson, D. C., Richardson, J. S.,

Terwilliger, T. C. \& Adams, P. D. (2012) Graphical tools for macromolecular crystallography in PHENIX, J Appl Crystallogr. 45, 581-586.

64. Morin, A., Eisenbraun, B., Key, J., Sanschagrin, P. C., Timony, M. A., Ottaviano, M. \& Sliz, P. (2013) Collaboration gets the most out of software, Elife. 2, e01456.

65. Meyer, P. A., Socias, S., Key, J., Ransey, E., Tjon, E. C., Buschiazzo, A., Lei, M., Botka, C., Withrow, J., Neau, D., Rajashankar, K., Anderson, K. S., Baxter, R. H., Blacklow, S. C., Boggon, T. J., Bonvin, A. M., Borek, D., Brett, T. J., Caflisch, A., Chang, C. I., Chazin, W. J., Corbett, K. D., Cosgrove, M. S., Crosson, S., Dhe-Paganon, S., Di Cera, E., Drennan, C. L., Eck, M. J., Eichman, B. F., Fan, Q. R., Ferre-D'Amare, A. R., Fromme, J. C., Garcia, K. C., Gaudet, R., Gong, P., Harrison, S. C., Heldwein, E. E., Jia, Z., Keenan, R. J., Kruse, A. C., Kvansakul, M., McLellan, J. S., Modis, Y., Nam, Y., Otwinowski, Z., Pai, E. F., Pereira, P. J., Petosa, C., Raman, C. S., Rapoport, T. A., Roll-Mecak, A., Rosen, M. K., Rudenko, G., Schlessinger, J., Schwartz, T. U., Shamoo, Y., Sondermann, H., Tao, Y. J., Tolia, N. H., Tsodikov, O. V., Westover, K. D., Wu, H., Foster, I., Fraser, J. S., Maia, F. R., Gonen, T., Kirchhausen, T., Diederichs, K., Crosas, M. \& Sliz, P. (2016) Data publication with the structural biology data grid supports live analysis, Nat Commun. 7, 10882.

66. Edgar, R. C. (2004) MUSCLE: multiple sequence alignment with high accuracy and high throughput, Nucleic Acids Res. 32, 1792-7.

67. Krissinel, E. \& Henrick, K. (2007) Inference of macromolecular assemblies from crystalline state, J Mol Biol. 372, 774-97.

68. Hawkins, C. J., Wang, S. L. \& Hay, B. A. (1999) A cloning method to identify caspases and their regulators in yeast: identification of Drosophila IAP1 as an inhibitor of the Drosophila caspase DCP-1, Proc Natl Acad Sci U S A. 96, 2885-90.

69. Jabbour, A. M., Puryer, M. A., Yu, J. Y., Lithgow, T., Riffkin, C. D., Ashley, D. M., Vaux, D. L., Ekert, P. G. \& Hawkins, C. J. (2006) Human Bcl-2 cannot directly inhibit the 
Caenorhabditis elegans Apaf-1 homologue CED-4, but can interact with EGL-1, J Cell Sci. 119, 2572-82.

70. Petros, A. M., Olejniczak, E. T. \& Fesik, S. W. (2004) Structural biology of the Bcl-2 family of proteins, Biochim Biophys Acta. 1644, 83-94. 


\section{Tables}

Table 1: Interactions of TANV16L with pro-apoptotic BH3 motif peptides. All affinities were measured using isothermal titration calorimetry and $K_{D}$ values given in $\mathrm{nM}$ as a mean of three independent experiments with SD. NB no binding detectable, nd denotes that data obtained did not allow determination of affinity and thermodynamic parameters, $\mathrm{N}$ denotes stoichiometry of the interaction.

\begin{tabular}{llll|lcc}
\hline Peptide & WT 16L & & & \multicolumn{1}{l}{$\mathbf{1 6 L} \mathbf{R 9 0 A}$} & $\Delta \mathbf{H}$ & $\mathbf{N}$ \\
& $\mathbf{K}_{\mathbf{D}}(\mathbf{n M})$ & $\Delta \mathbf{H}$ & $\mathbf{N}$ & $\mathbf{K}_{\mathbf{D}}(\mathbf{n M})$ & & \\
\hline Bak & $38 \pm 4$ & $-4.27 \pm 0.07$ & $0.99 \pm 0.08$ & $2325 \pm 261$ & $-4.07 \pm 0.26$ & $0.95 \pm 0.02$ \\
Bax & $70 \pm 5$ & $-4.55 \pm 0.2$ & $1.01 \pm 0.06$ & $2301 \pm 374$ & $-7.36 \pm 0.37$ & $1.03 \pm 0.03$ \\
Bok & $\mathrm{NB}$ & $\mathrm{NB}$ & $\mathrm{NB}$ & $\mathrm{NB}$ & $\mathrm{NB}$ & $\mathrm{NB}$ \\
Bad & $219 \pm 34$ & $-6.3 \pm 1.3$ & $0.95 \pm 0.07$ & $10206 \pm 1570$ & $-4.45 \pm 0.20$ & $0.87 \pm 0.06$ \\
Bid & $719 \pm 66$ & $-4.13 \pm 0.5$ & $1.02 \pm 0.07$ & nd & nd & nd \\
Bik & $1250 \pm 111$ & $-2.51 \pm 0.31$ & $0.85 \pm 0.03$ & $14356 \pm 1370$ & $-3.17 \pm 0.75$ & $1.12 \pm 0.05$ \\
Bim & $180 \pm 15$ & $-4.93 \pm 0.31$ & $0.90 \pm 0.03$ & $1766 \pm 320$ & $-6.16 \pm 0.63$ & $0.98 \pm 0.1$ \\
Bmf & $606 \pm 76$ & $-5.83 \pm 0.52$ & $0.98 \pm 0.06$ & nd & nd & nd \\
Hrk & $3220 \pm 301$ & $-5.07 \pm 0.10$ & $1.02 \pm 0.09$ & nd & nd & nd \\
Noxa & NB & NB & NB & NB & NB & NB \\
Puma & $468 \pm 47$ & $-5.87 \pm 0.15$ & $0.88 \pm 0.08$ & $911 \pm 39$ & $-1.17 \pm 0.1$ & $0.99 \pm 0.08$ \\
\hline
\end{tabular}

\begin{tabular}{l|lcc}
\hline Peptide & \multicolumn{1}{|l}{$\mathbf{1 6 L \_ K 5 2 A}$} & \multicolumn{1}{l}{$\mathbf{H}$} & $\mathbf{N}$ \\
& $\mathbf{K}_{\mathbf{D}}(\mathbf{n M})$ & & \\
\hline Bak & $113 \pm 3$ & $-8.24 \pm 0.73$ & $1.03 \pm 0.04$ \\
Bax & $266 \pm 11$ & $-6.23 \pm 0.32$ & $1.05 \pm 0.04$ \\
Bok & NB & NB & NB \\
Bad & $5857 \pm 732$ & $-3.63 \pm 0.40$ & $0.89 \pm 0.04$ \\
Bid & $976 \pm 126$ & $-5.8 \pm 0.26$ & $1.04 \pm 0.03$ \\
Bik & $3382 \pm 85$ & $-5,67 \pm 0.11$ & $0.97 \pm 0.06$ \\
Bim & $558 \pm 27$ & $-4.61 \pm 0.29$ & $1.01 \pm 0.006$ \\
Bmf & nd & nd & nd \\
Hrk & nd & nd & nd \\
Noxa & NB & NB & NB \\
Puma & $1010 \pm 130$ & $2.95 \pm 0.15$ & $1.04 \pm 0.02$ \\
\hline
\end{tabular}


Table 2: X-ray data collection and refinement statistics. Values in parentheses are for the

\begin{tabular}{|c|c|c|c|}
\hline & TANV16L:Bax BH3 & $\begin{array}{l}\text { TANV16L:Puma } \\
\text { BH3 }\end{array}$ & TANV16L:Bim BH3 \\
\hline \multicolumn{4}{|l|}{ Data collection } \\
\hline Space group & $\mathrm{P} 4_{3} 2_{1} 2$ & $\overline{\mathrm{P} 22_{1} 2_{1} 2_{1}}$ & $\mathrm{P} 3_{2} 2_{1}$ \\
\hline $\begin{array}{l}\text { Cell dimensions } \\
\mathrm{a}, \mathrm{b}, \mathrm{c}(\AA) \\
\alpha, \beta, \gamma\left({ }^{\circ}\right)\end{array}$ & $\begin{array}{l}55.38,55.38,126.94 \\
909090\end{array}$ & $\begin{array}{l}54.09,54.87,60.22 \\
90,90,90\end{array}$ & $\begin{array}{l}59.65,59.65,90.90 \\
90,90,120\end{array}$ \\
\hline Wavelength $(\AA)$ & 0.9537 & 0.9537 & 0.9537 \\
\hline Resolution $(\AA)$ & $33.33-2.12(2.19-2.12)$ & $32.45-1.85(1.91-1.85)$ & $44.92-3.00(3.11-3.00)$ \\
\hline $\mathrm{R}_{\text {sym }}$ or $\mathrm{R}_{\text {merge }}$ & $0.097(2.67)$ & $0.066(1.55)$ & $0.168(1.50)$ \\
\hline $\mathrm{I} / \sigma \mathrm{I}$ & $11.2(0.8)$ & $11.1(0.9)$ & $4.3(0.7)$ \\
\hline $\begin{array}{l}\text { Completeness (\%) } \\
\mathrm{CC}_{1 / 2}\end{array}$ & $\begin{array}{l}99.86(99.65) \\
0.99(0.29)\end{array}$ & $\begin{array}{l}99.51(97.62) \\
0.99(0.40)\end{array}$ & $\begin{array}{l}99.9(100) \\
0.99(0.34)\end{array}$ \\
\hline Redundancy & $8.6(6.6)$ & $5.5(4.7)$ & $4.7(4.6)$ \\
\hline \multicolumn{4}{|l|}{ Refinement } \\
\hline No. reflections & 11838 & 15799 & 7992 \\
\hline $\mathrm{R}_{\text {work }} / \mathrm{R}_{\text {free }}$ & $0.239 / 254$ & $0.195 / 0.223$ & $0.242 / 0.276$ \\
\hline Clashscore & 0.5 & 2.17 & 2.66 \\
\hline \multicolumn{4}{|l|}{ No. atoms } \\
\hline Protein & 1291 & 1369 & 1298 \\
\hline Ligand/ion & 2 & 1 & 1 \\
\hline Water & 23 & 91 & 8 \\
\hline \multicolumn{4}{|l|}{ B-factors } \\
\hline Protein & 65.68 & 51.74 & 72.84 \\
\hline Ligand/ion & 84.20 & 86.29 & 63.59 \\
\hline Water & 60.76 & 50.89 & 65.12 \\
\hline \multicolumn{4}{|l|}{ R.m.s. deviations } \\
\hline Bond lengths $(\AA)$ & 0.003 & 0.006 & 0.003 \\
\hline Bond angles $\left(^{\circ}\right)$ & 0.44 & 0.67 & 0.51 \\
\hline
\end{tabular}

highest resolution shell. 


\section{Figure legends}

Figure 1: Sequence alignment of TANV16L with pro-survival Bcl-2 family members. The sequences of tanapoxvirus 16L (uniprot accession number: A7XCC0), deerpoxvirus DPV022 (uniprot accession number: Q08FX8), vaccinia virus F1L (uniprot accession number: O57173), myxomavirus M11L (uniprot accession number: Q85295) and human Bcl- $\mathrm{x}_{\mathrm{L}}$ (uniprot accession number: Q07817) were aligned using MUSCLE [66]. Secondary structure elements are marked based on the crystal structure of TANV16L, and BH motifs are boxed and shown in bold [70]. The regions of helix are marked ' $\mathrm{H}$ ' and unstructured loops with a bar above the sequence, conserved residues are denoted by '*', with highly conservative substitutions indicated by ':' and conserved substitutions indicated by '.

Figure 2: TANV16L engages a broad spectrum of BH3 motif peptides of pro-apoptotic Bcl-2 proteins. The affinities of recombinant TANV16L for BH3 motif peptides (26-mers, except for a Bid 34-mer and Bax 28-mers) were measured using ITC and the raw thermograms shown. $\mathrm{K}_{\mathrm{D}}$ values (in $\mathrm{nM}$ ) are the means of 3 experiments \pm SD NB: no binding detected. The binding affinities are tabulated in Table 1.

Figure 3: TANV16L is able to prevent Bak and Bax induced yeast growth arrest. Yeast cotransformed with constructs encoding Bax or Bak and the indicated pro-survival proteins, each under the control of an inducible (GAL) promoter, were spotted onto inducing galactose (“ON") or repressing glucose (“OFF") plates as 5-fold serial dilutions. Images are representative of 2 independent experiments.

Figure 4: Crystal structures of TANV16L bound to Bax, Puma and Bim BH3 motifs. 
(a) TANV16L (slate) in complex with the Bax BH3 motif (yellow). TANV16L helices are labelled $\alpha 1-\alpha 7$. The left-hand view is of the hydrophobic binding groove of one protomer formed by helices $\alpha 3-\alpha 5$, the right-hand view is the domain swapped dimer viewed along the 2-fold symmetry axis between the domain-swapped $\alpha 1$ helices. (b) TANV16L (slate) in complex with the Bim BH3 domain (dark green) (c) DPV022 (cyan) in complex with the Bax BH3 domain (yellow) [29]. The view is as in (a). (d) TANV16L (slate) in complex with the Puma BH3 domain (olive) (e) Myxoma virus M11L (green) in complex with Bak BH3 (magenta). All structures were aligned using DALI pairwise alignment [35] and the view is as in (a). The view in the right-hand panels in (b) and (c) are as in (a). (f) Superimposition of the C $\alpha$ backbone of TANV16L:Bax BH3 (slate and yellow) with DPV022:Bax BH3 (cyan and yellow, PDB ID 4UF2). (g) TANV16L:Bax BH3 (slate and yellow) with DPV022:Bak BH3 (cyan and magenta, PDB ID 4UF1) (h) TANV16L:Puma BH3 (slate and green) (green) with human Mcl-1:Puma BH3 (raspberry and green, PDB ID 6QFM), the most similar structure to that of TANV16L:Puma BH3 identified using Dali. All views are into the canonical ligand binding groove formed by helices $\alpha 2-5$. Superimpositions were generated using pairwise Dali alignment [35].

Figure 5: Detailed view of the TANV16L: Bax, Bim and Puma BH3 interfaces and mutation sites. (a) Surface depiction of the TANV16L: Bax BH3 complex. The TANV16L surface, backbone and floor of the binding groove are shown in grey and pink respectively, while Bax BH3 is shown as a yellow ribbon. The four key hydrophobic residues of Bax BH3 (L157, L161, I164 and 168L) are protruding into the binding groove, and the conserved salt-bridge formed by Bax D166 and TANV16L R90 are labeled, as well as residues involved in hydrogen bonds. (b) TANV16L:Bim BH3 with the surface of TANV16L is shown as in (a), and Bim BH3 is shown in dark green. The four key hydrophobic residues of Bim BH3 (I157, 
L161, I164 and F168) are protruding into the binding groove, and the conserved salt-bridge formed by Bim D166 and TANV16L R90 are labeled, as well as residues involved in hydrogen bonds. Interactions are denoted as black dotted lines. (c) TANV16L:Puma BH3 is shown as in (a), with Puma BH3 shown in olive. The four key hydrophobic residues of Puma BH3 (I136, L140, M143 and L147) are protruding into the binding groove, and the conserved salt-bridge formed by Puma D145 and TANV16L R90 are labeled, as well as residues involved in hydrogen bonds. Interactions are denoted as black dotted lines. (d) crystal packing of TANV16L:Puma BH3 complex. (e) TANV16L is shown as a grey surface, with locations of mutations used to investigate the binding site shaded in red. The views were selected for the clearest view of the groove interactions in each case. (f) $2 \mathrm{Fo}-\mathrm{Fc}$ electron density maps of TANV16L:Bax BH3 complex interface. (g) 2Fo-Fc electron density maps of TANV16L:Puma BH3 complex interface. (h) 2Fo-Fc electron density maps of TANV16L:Bim BH3 complex interface. All maps were contoured at $1.5 \sigma$. The $\mathrm{N}$ - and Ctermini of the $\mathrm{BH} 3$ peptides are labelled and the structures aligned as in Figure 4. The view was selected for clarity of the $\mathrm{BH} 3$ peptide side chains.

Figure 6: Sedimentation velocity analytical ultracentrifugation analysis of (a,b) TANV16L on its own at initial concentrations of $0.2 \mathrm{mg} / \mathrm{ml}$ (black), $0.4 \mathrm{mg} / \mathrm{ml}$ (orange) and $0.8 \mathrm{mg} / \mathrm{ml}$ (purple) and (c,d) TANV16L at an initial concentration of $0.2 \mathrm{mg} / \mathrm{ml}$ unliganded (black) and in complex with Bim (blue), Bax (green) or Puma (red). Top panels - Residuals resulting from the sedimentation coefficient distribution $c(s)(\mathbf{a , c})$ and distribution of molar masses $c(M)(\mathbf{b}, \mathbf{d})$ best fits are plotted as a function of radial position. The residuals for the given curves are shown in the same colour above the plots. $\mathrm{M}$ denotes monomeric, $\mathrm{D}$ dimeric and $\mathrm{T}$ tetrameric species. 
Figure 7: The affinities of recombinant TANV16L_R90A mutant for BH3 motif peptides (26-mers, except for a Bid 34-mer and Bax 28-mers) were measured using ITC and the raw thermograms shown. $\mathrm{K}_{\mathrm{D}}$ values (in $\mathrm{nM}$ ) are the means of 3 experiments \pm SD NB: no binding detected. nd: not determined with data obtained not suitable for precise determination of affinities and thermodynamic parameters. The binding affinities are tabulated in Table 1.

Figure 8: The affinities of recombinant TANV16L_K52A mutant for BH3 motif peptides (26-mers, except for a Bid 34-mer and Bax 28-mers) were measured using ITC and the raw thermograms shown. $\mathrm{K}_{\mathrm{D}}$ values (in $\mathrm{nM}$ ) are the means of 3 experiments \pm SD NB: no binding detected. nd: not determined with data obtained not suitable for precise determination of affinities and thermodynamic parameters. The binding affinities are tabulated in Table 1.

Figure 9: Cartoon diagrams of dimeric topologies in the Bcl-2 family (a) Vaccinia virus N1L homodimer (cyan, PDB ID 2UXE) [38]. (b) Grouper iridovirus GIV66 (green, PDB ID

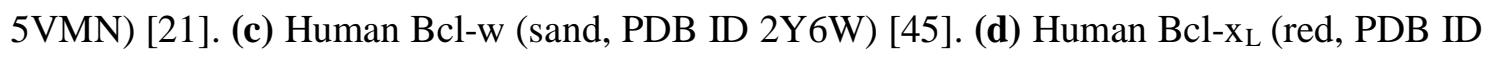
1R2D) [41]. (e) Human Bak core-latch dimer (magenta, PDB ID 4U2U) [46]. (f) Human Bax core-latch dimer (blue, PDB ID 4ZIE) [47]. (g) Catfish Bax groove-tail dimer (yellow and orange, PDB ID 5W63) [48]. 


\section{Acknowledgements}

We thank staff at the MX beamlines at the Australian Synchrotron for help with X-ray data collection. We thank the ACRF for their support of the Eiger MX detector at the Australian Synchrotron MX2 beamline and the Comprehensive Proteomics Platform at La Trobe University for core instrument support. This research was funded by the Australian Research Council (Fellowship FT130101349 to MK and DE190100806 to TPSC), National Health and Medical Research Council of Australia (CDA fellowship 637372 and Project Grant APP1007918 to MK) and La Trobe University (Scholarship to CDS, MIA, AJ and REI).

\section{Author Contributions}

Chathura D. Suraweera: Acquisition, analysis and interpretation of data; Drafting and revising the article.

Mohd Ishtiaq Anasir: Acquisition, analysis and interpretation of data.

Airah Javorsky: Acquisition, analysis and interpretation of data;

Srishti Chugh: Acquisition, analysis and interpretation of data.

Rachael E. Impey: Acquisition, analysis and interpretation of data.

Muhammad Hasan Zadeh: Acquisition, analysis and interpretation of data.

Tatiana P. Soares da Costa: Acquisition, analysis and interpretation of data; Drafting and revising the article.

Mark G. Hinds: Conception and design; Analysis and interpretation of data; Drafting and revising the article;

Marc Kvansakul: Conception and design; Acquisition of data; Analysis and interpretation of data; Drafting and revising the article. 
bioRxiv preprint doi: https://doi.org/10.1101/2020.01.21.914671; this version posted April 28, 2020. The copyright holder for this preprint (which was not certified by peer review) is the author/funder. All rights reserved. No reuse allowed without permission.

\section{Conflicts of interest}

The authors declare no competing financial interests in relation to the work described. 
TANV16L (Q9DHU6) DPV022 (Q08FX8) MVA_F1LAN59(057173) M11L $(085295)$

BCl-xLA28-80 (207817)
10

20 30 50

60

1 MENSCNFN SIKNVIVFYINEKALIEEKK LSCYE-NILLNLIKEDCENIMI KYKPNLSYICSLLKVD

1 MEAAIEFD IVKKLLNIYINDICTMGEKRI LNNYE-KS ILDRIYKSCEY IKम HYELDFNSMYNQININ 60 ------ H HVMMAVRYYMSKORLDDLYR LPTKT-R Y IDI INI YCDKVS DYNRDMNIMYDMASTK 1 -----MM RLKTAVYDYLNDV------D TECTE-MDLLCQLSNCCDF INETYAKNYDTLYDIMERD 1 ------MS SNRELVYDELSYKISSOKGYSU SQF IPMAAVKOALREAGDEFEN RYRRAF SDLTSQLHIT

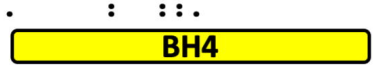

$\alpha 4$ $\alpha 5$ НННнННнННнННнННнННН

80

90

100

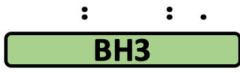

TANV16L DPV022

MVA_F1LAN59

M11L

BCl-XLA28-80

TANV16L DPV022 MVA_F1LAN59 M11L BCl-XLA28-80

68 DTSEENIKHIKDQII SLENDNRPSVKLAI-ISLISMIVEMNGYKGKN-IPMSFLI-EDIALKI-SEN

68 DIT---TSDIKSKI I SLLIDSRPSVKLAT-LSFISLIAEKWGEKNRT-KIMEILS-NEIVEKI-SNN

119 SFT---VYDINNEVN ILMDNKGLGVRLAT-ISFITELCRRCMNPVKT-IKMFTLLSHTIC-------

56 ILS-YNIVNIKNTL- FALRDASPSVKLAT-LTLLASVI KKLNKIQHTDAAMFS----EVIDGI-VAE

116 PGT---AYQSFEQVVIEIFRDG---VNWGRIVAFFSFGdALCVESVD--KEMQVLVS-RIAAWMATYL

\section{BH1}

$\alpha 7$

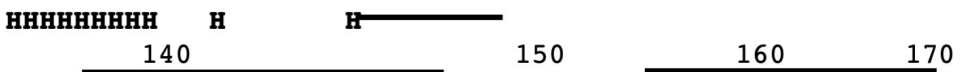

132 SEDL NFIN---I-------KNKQKS--FILK-K--V YLFWWVSILCLLGYFIR NITKT------

129 GKDF DFID---R-------DDDDI DDYVLITN--YI KITIFGAILGITAYYI \&KYLLKSIF---

175 DDCFYDYITDISP-------PDNTI NT--STRE--YI------KLIGITAIMFA TYKTLKYMIG-

116 EQQV GF IQKKCK-------YNTTY ---NVRSGGCKI SVYLTAAVVGFVAYGIIK-----WYRGT

175 NDHLL PWIOENGGWDTFVELYGNNAA---AESRKGQER FNRWFLTGMTVAGVVLI G----SLFSRK 
1. Bak control 2. Bak/Bcl- $x_{L}$ 3. Bak/16L

4. Bax control 5. Bax/Bcl- $\mathrm{X}_{\mathrm{L}}$ 6. Bax/16L 


\section{a}

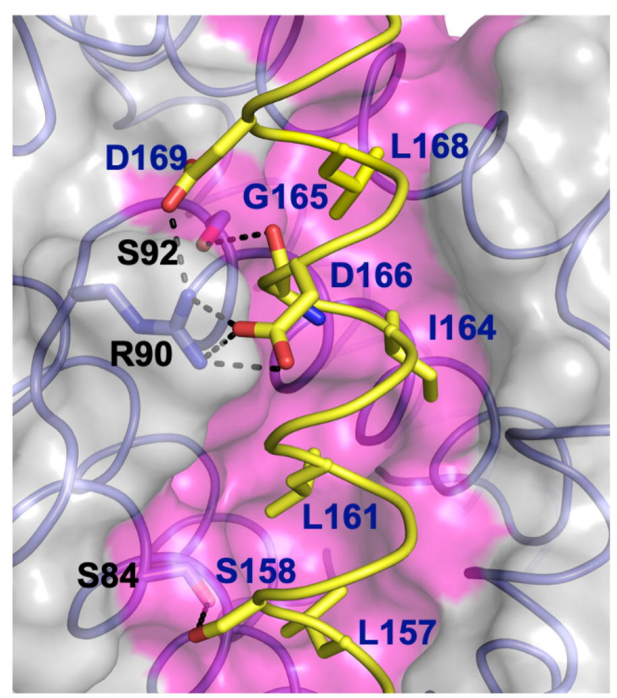

TANV16L: Bax BH3

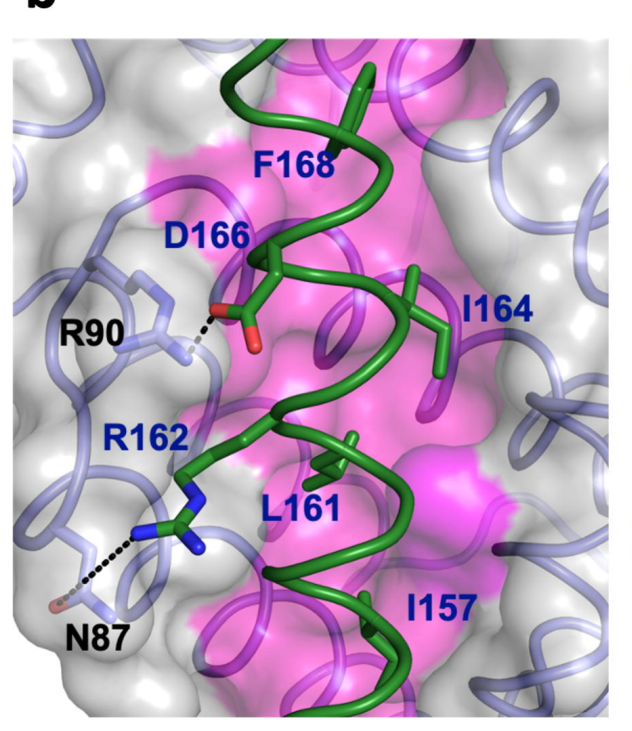

TANV16L: Bim BH3

C

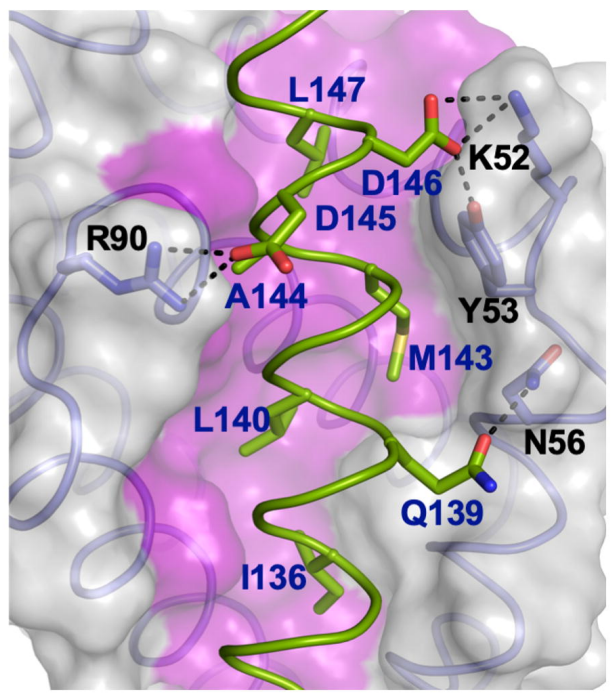

TANV16L: Puma BH3 d

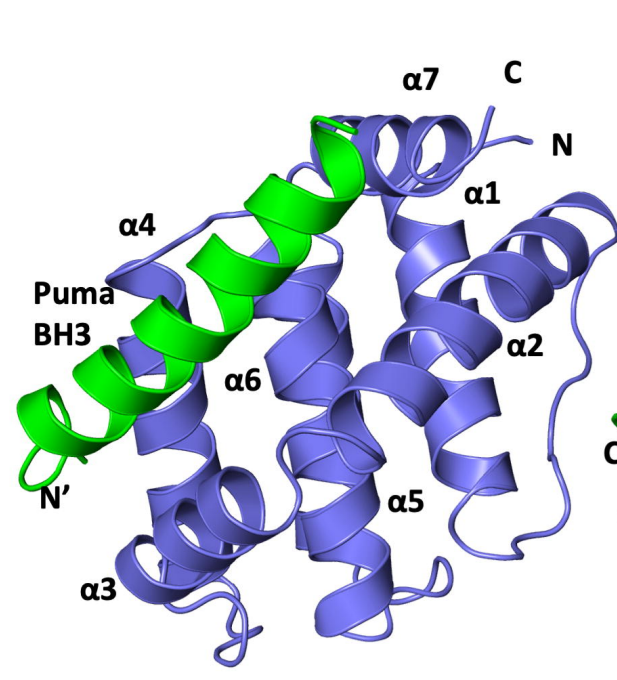

TANV16L: Puma BH3 crystal contact

f

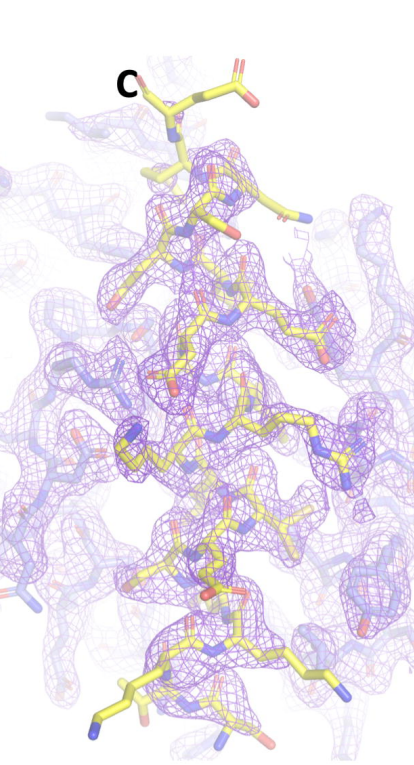

N

TANV16L: Bax BH3 g

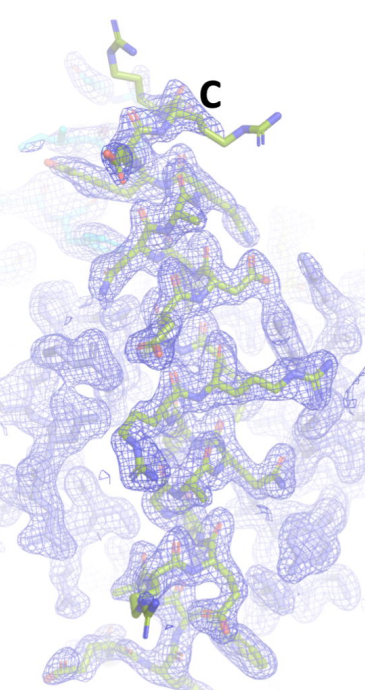

$\mathbf{N}$

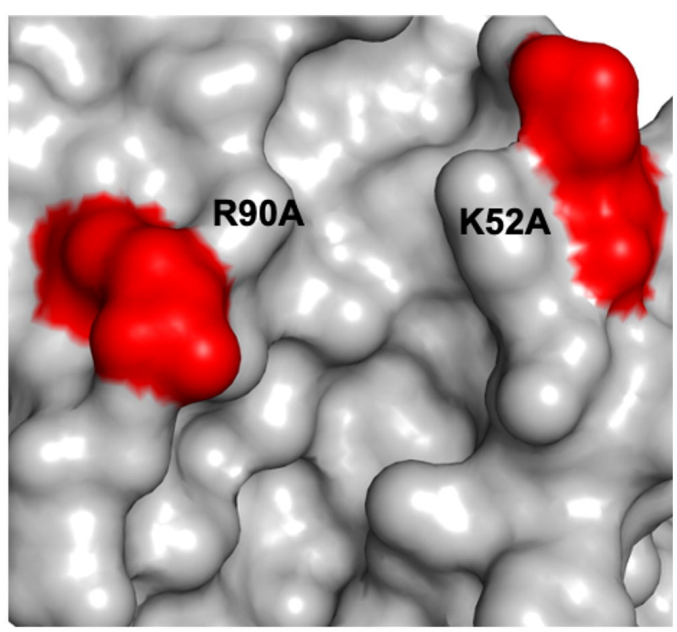

TANV16L mutants

h

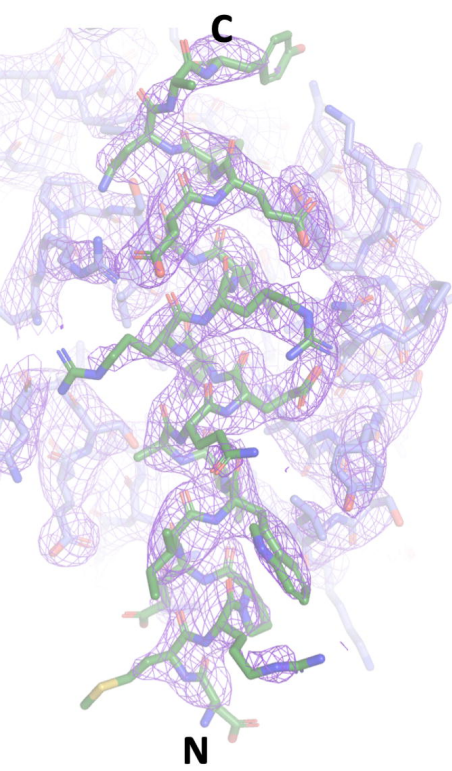


bioRxiv preprint doi: https://doi-org/101101/2020 0121.914671: this version posted Aprit 28, 2020. The copyright holder for this preprint dubligh
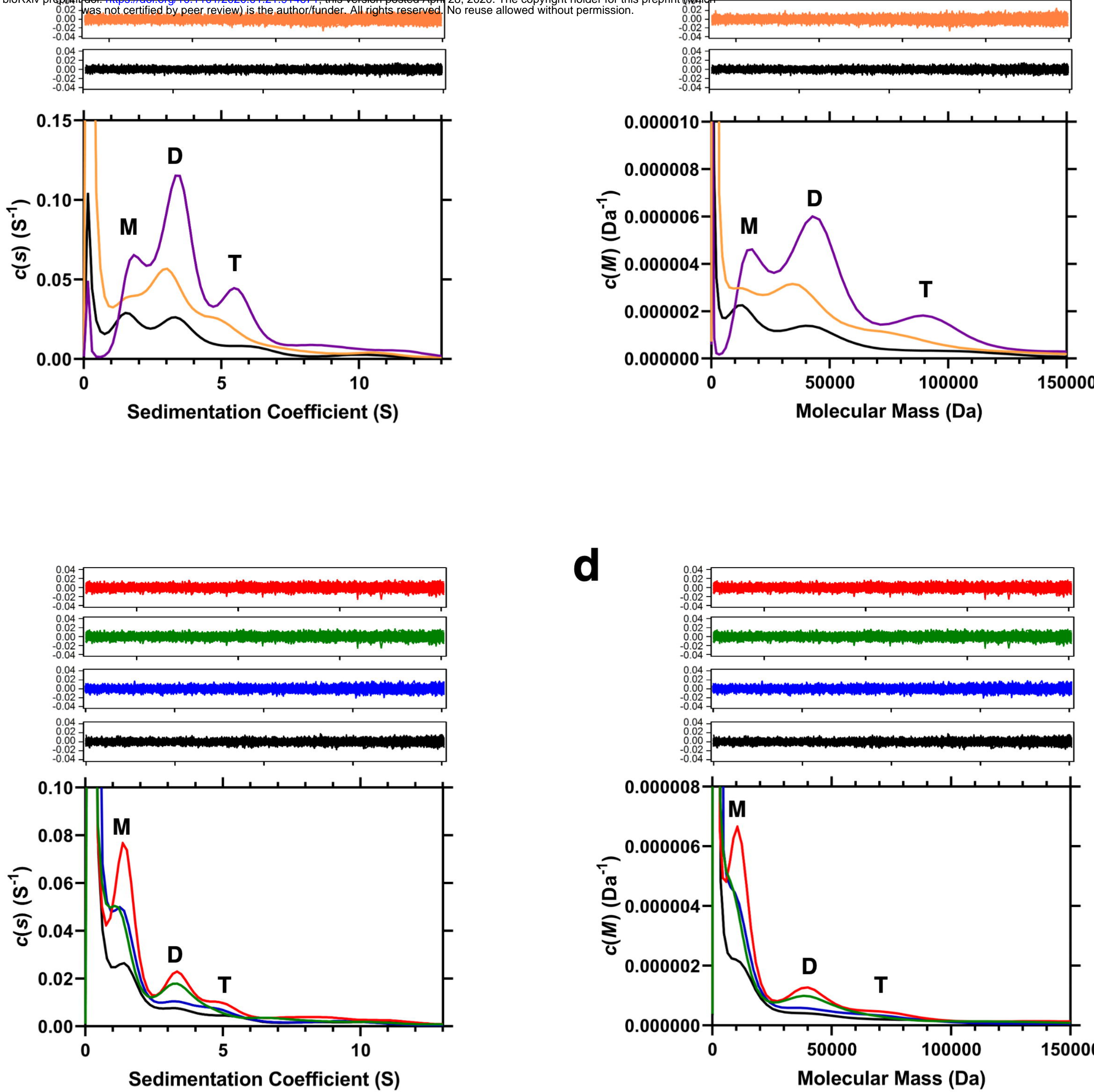

d

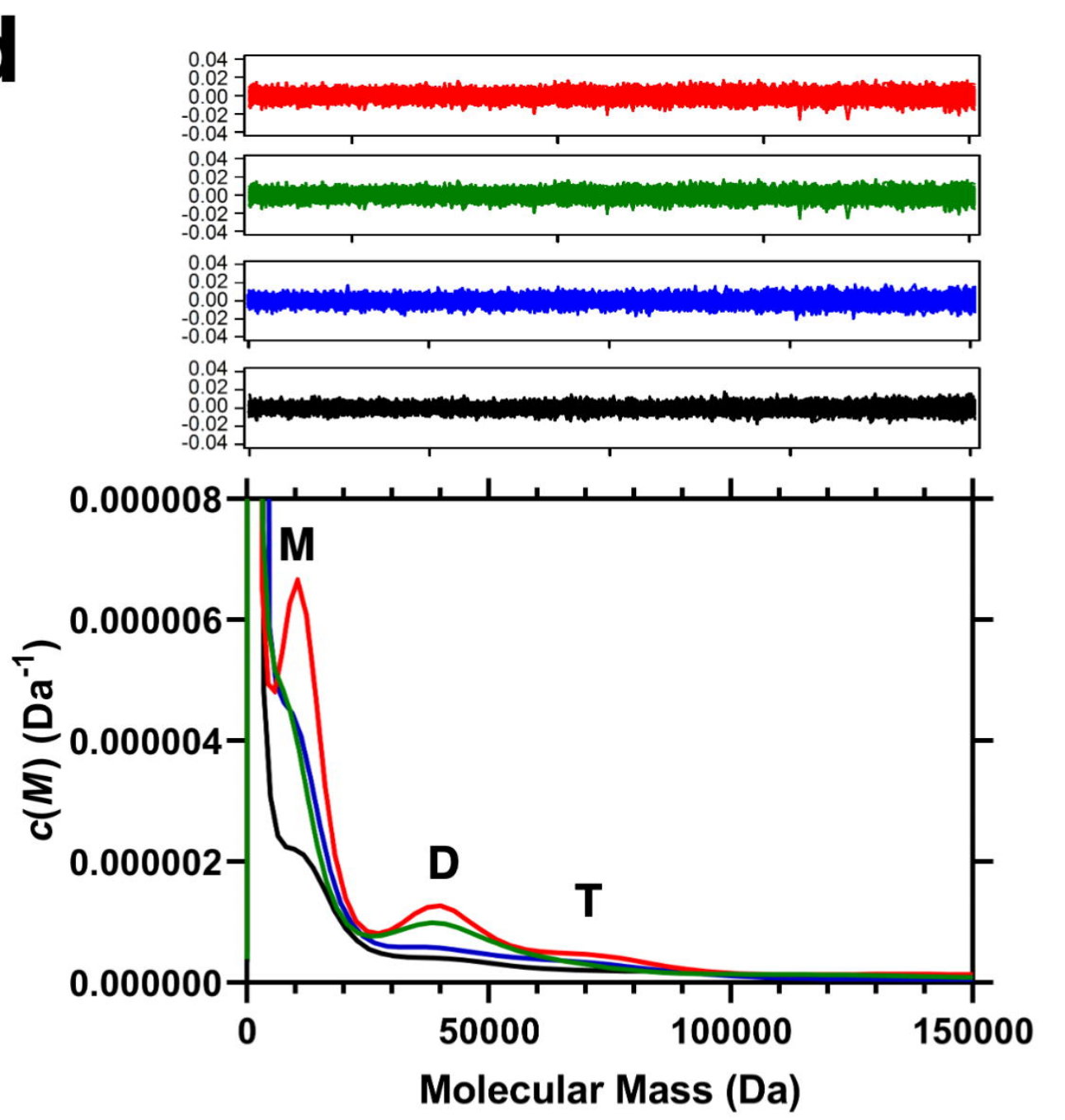


TANV16L_R90A: Bak

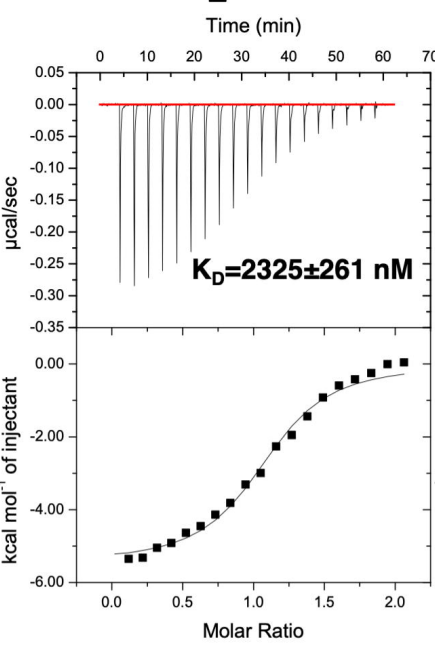

TANV16L_R90A: Bid

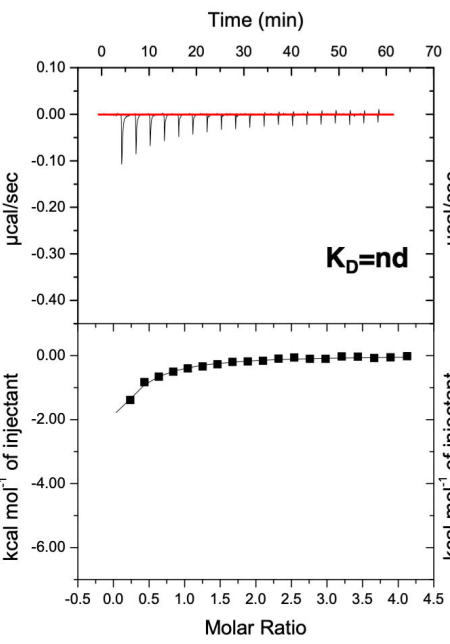

TANV16L_R90A: Hrk

Time (min)

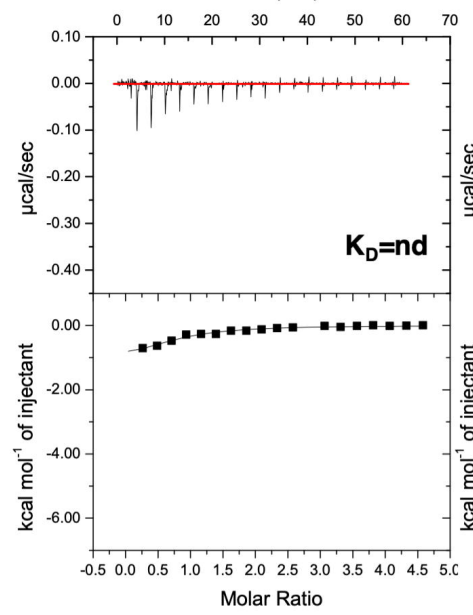

TANV16L_R90A: Bax

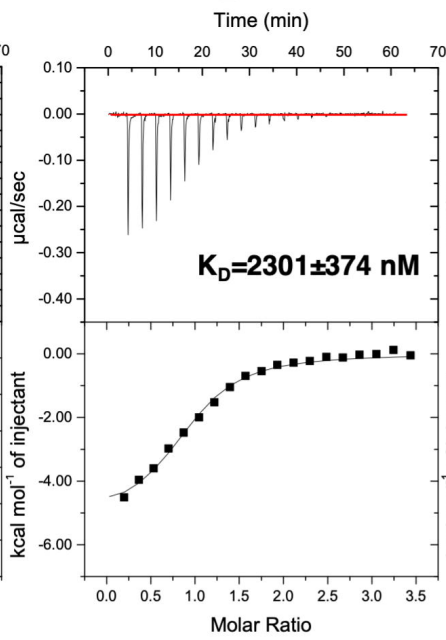

TANV16L_R90A: Bik

Time (min)

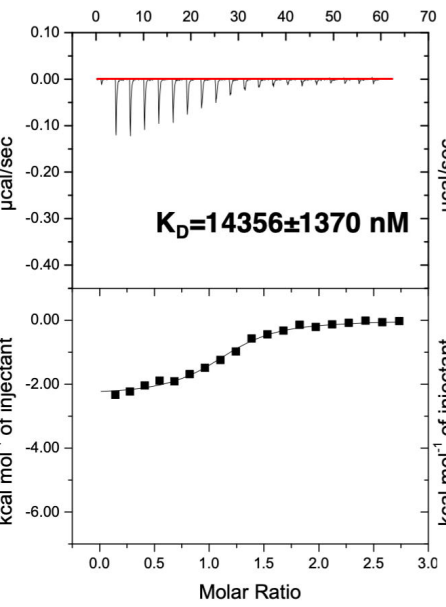

TANV16L_R90A: Noxa

Time ( $\mathrm{min}$ )

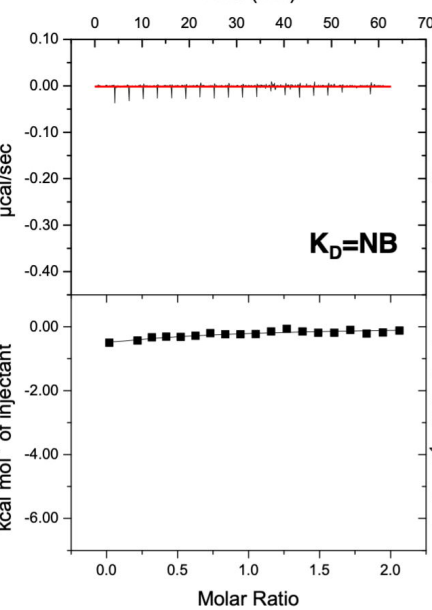

TANV16L_R90A: Bok Time (min)

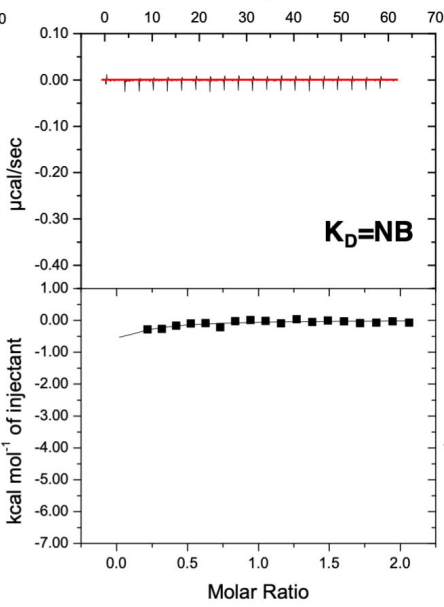

TANV16L_R90A: Bim

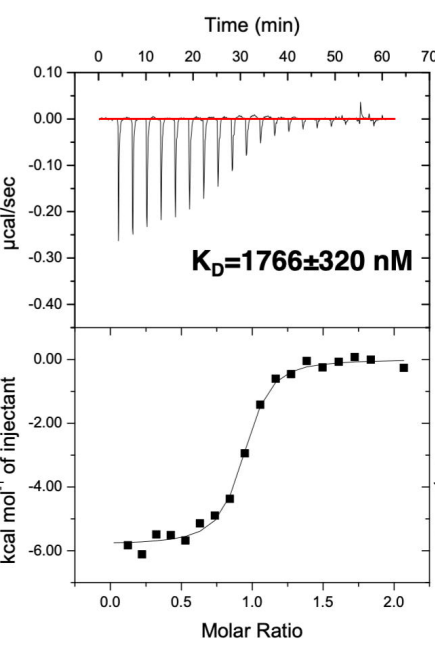

TANV16L_R90A: Puma

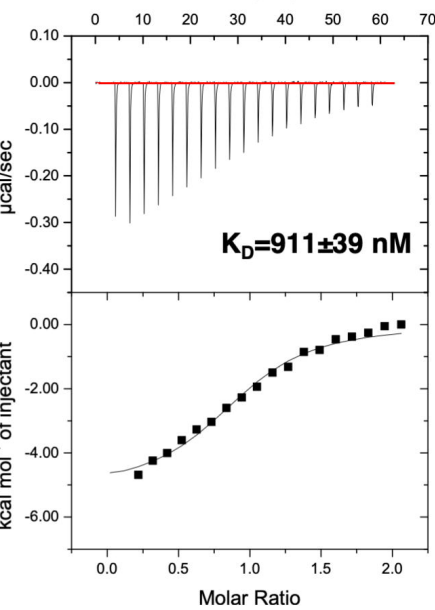

TANV16L_R90A: Bad Time (min)

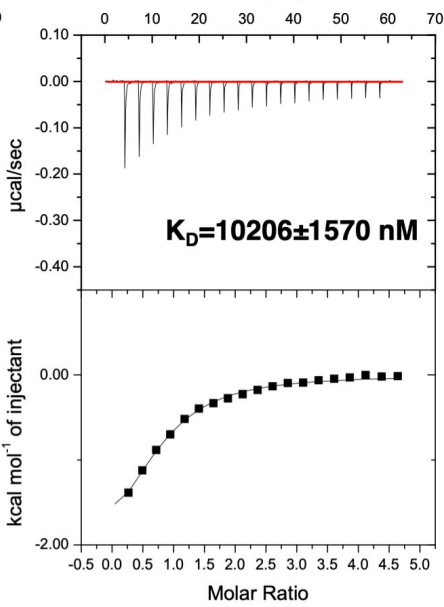

TANV16L_R90A: Bmf Time (min)

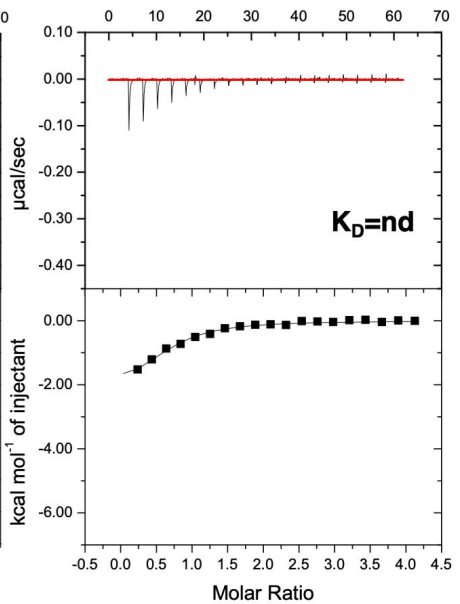


TANV16L_K52A: Bak

Time (min)

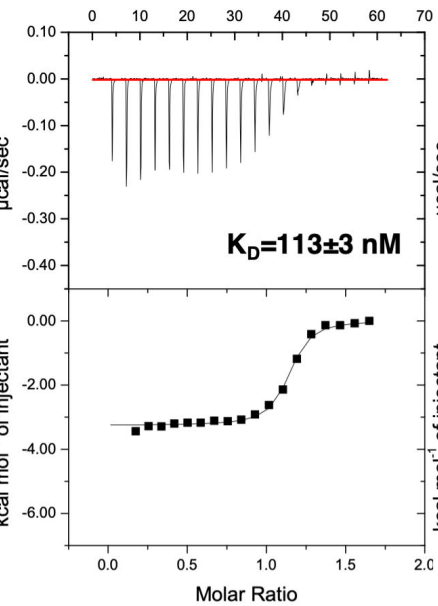

TANV16L_K52A: Bid

Time (min)

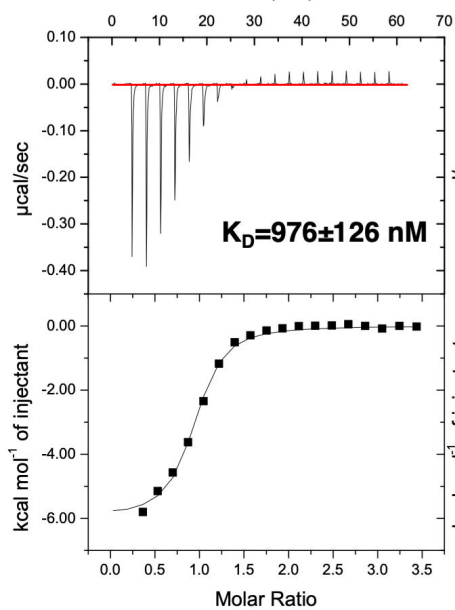

TANV16L_K52A: Hrk

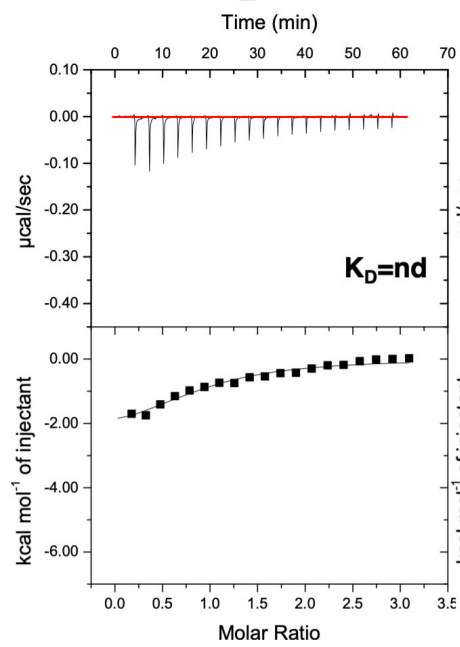

TANV16L_K52A: Bax

TANV16L_K52A: Bok

TANV16L_K52A: Bad

Time (min)

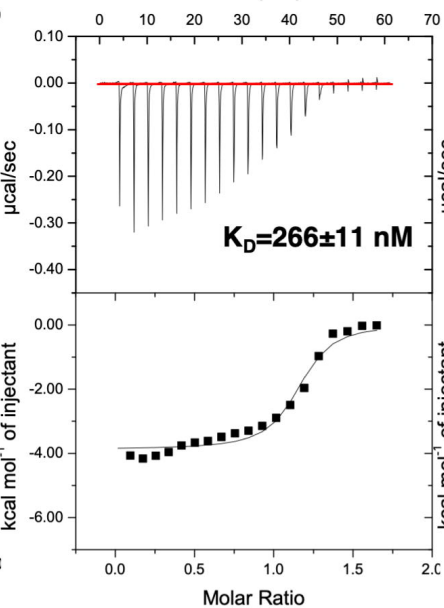

TANV16L_K52A: Bik

Time (min)

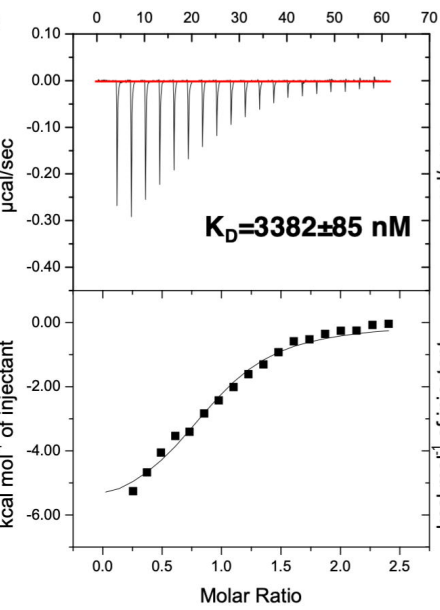

TANV16L_K52A: Noxa

Time (min)

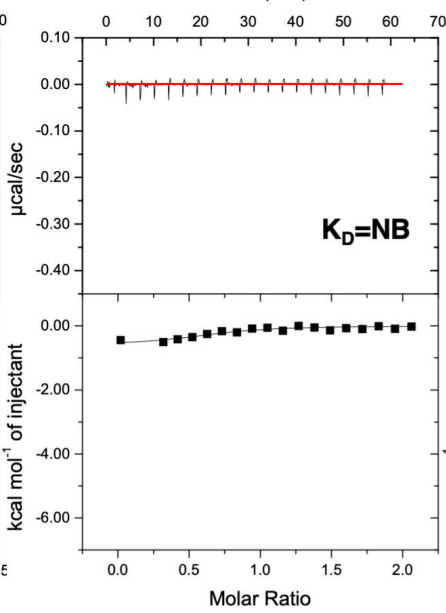

Time (min)

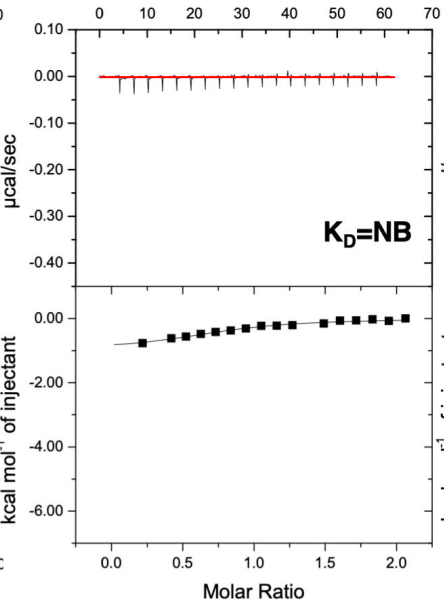

TANV16L_K52A: Bim

Time (min)

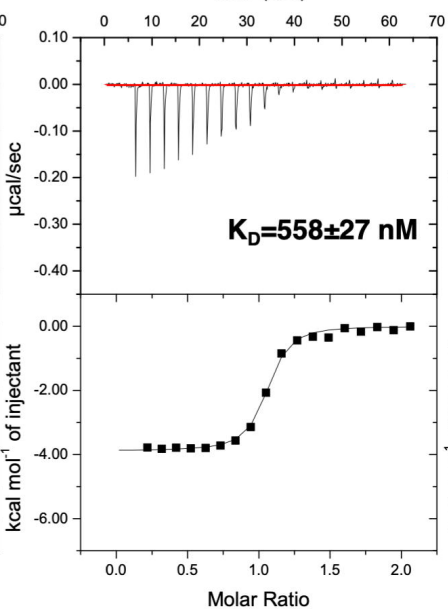

TANV16L_K52A: Puma

Time (min)

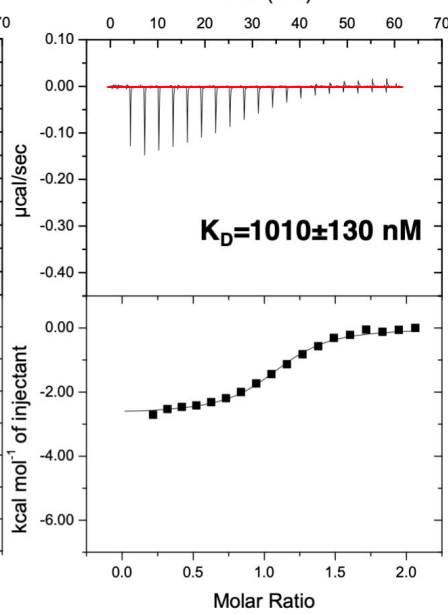

TANV16L_K52A: Bmf

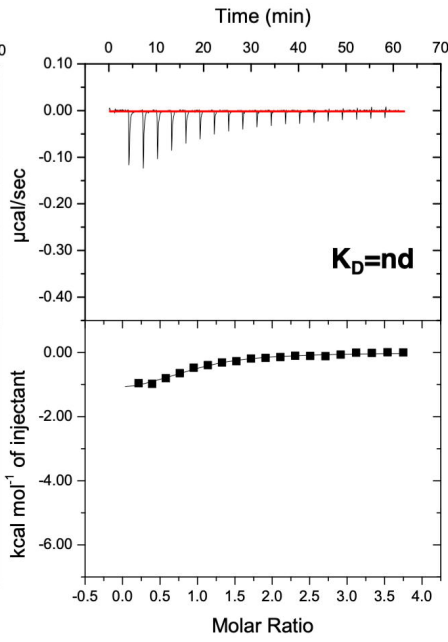




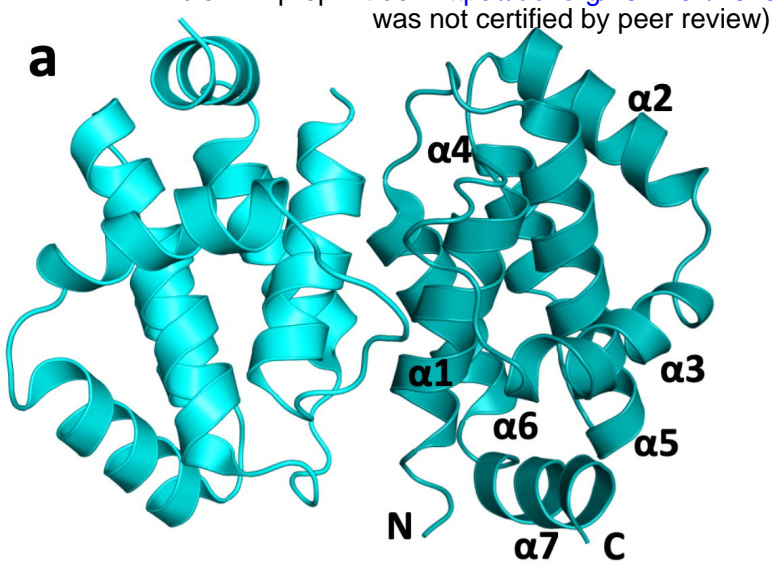

N1L

c

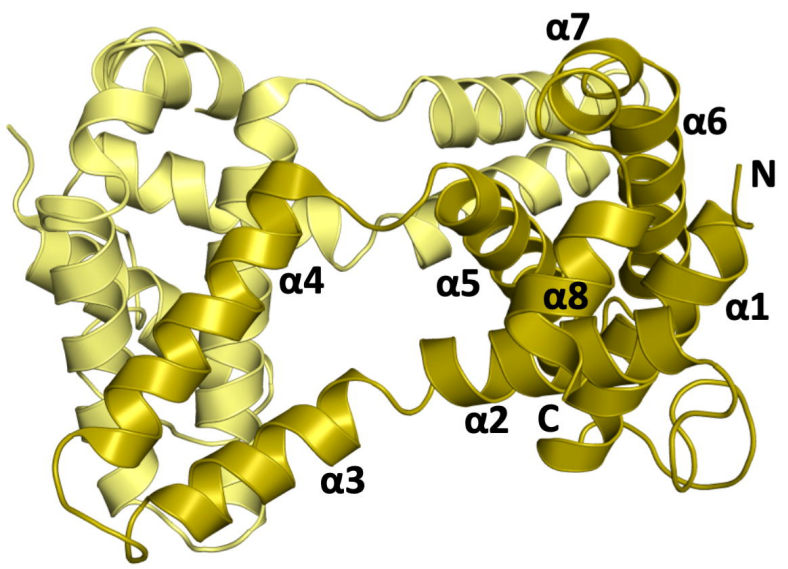

Bcl-w

e
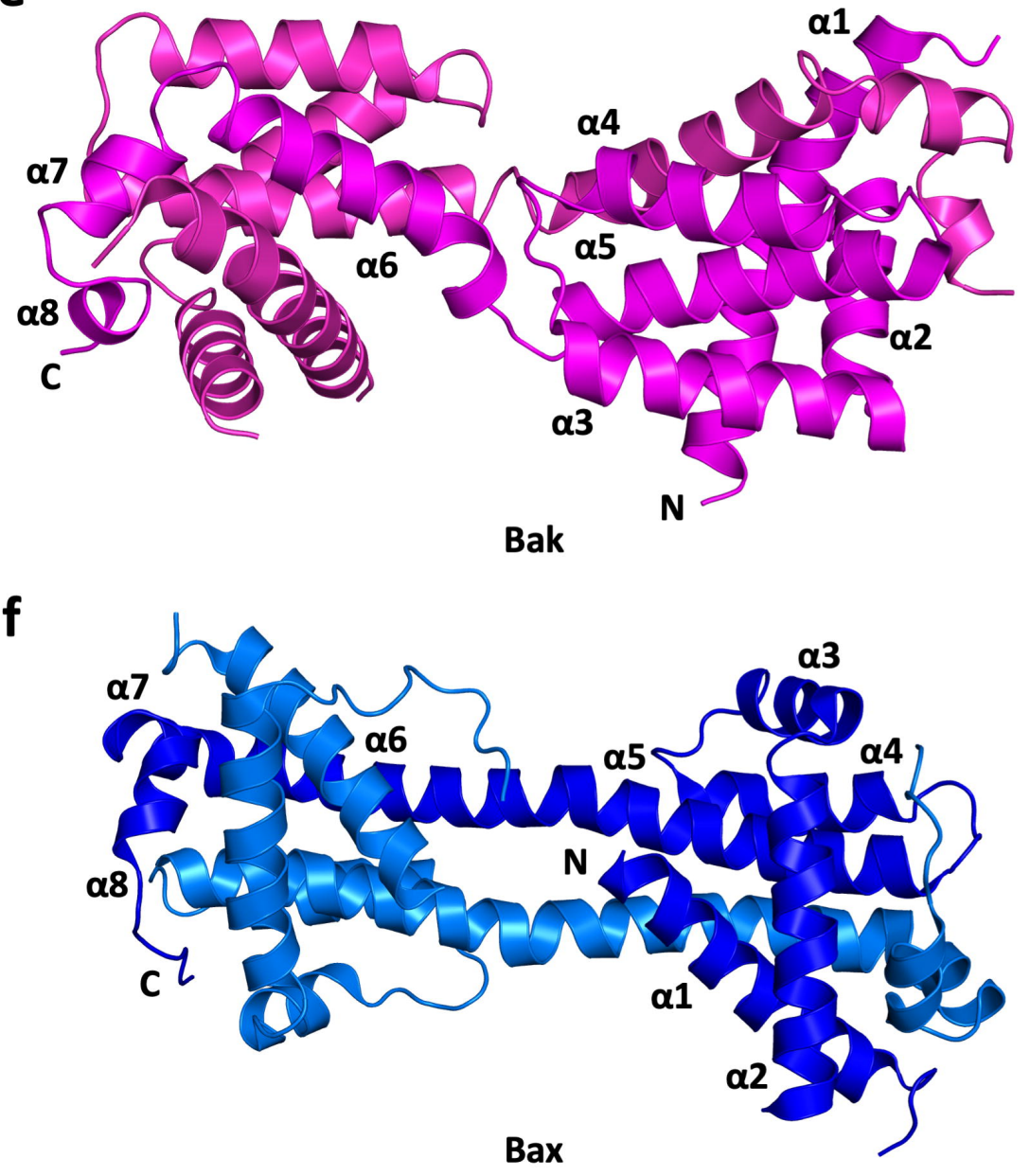

Bcl-- ${ }_{L}$

g
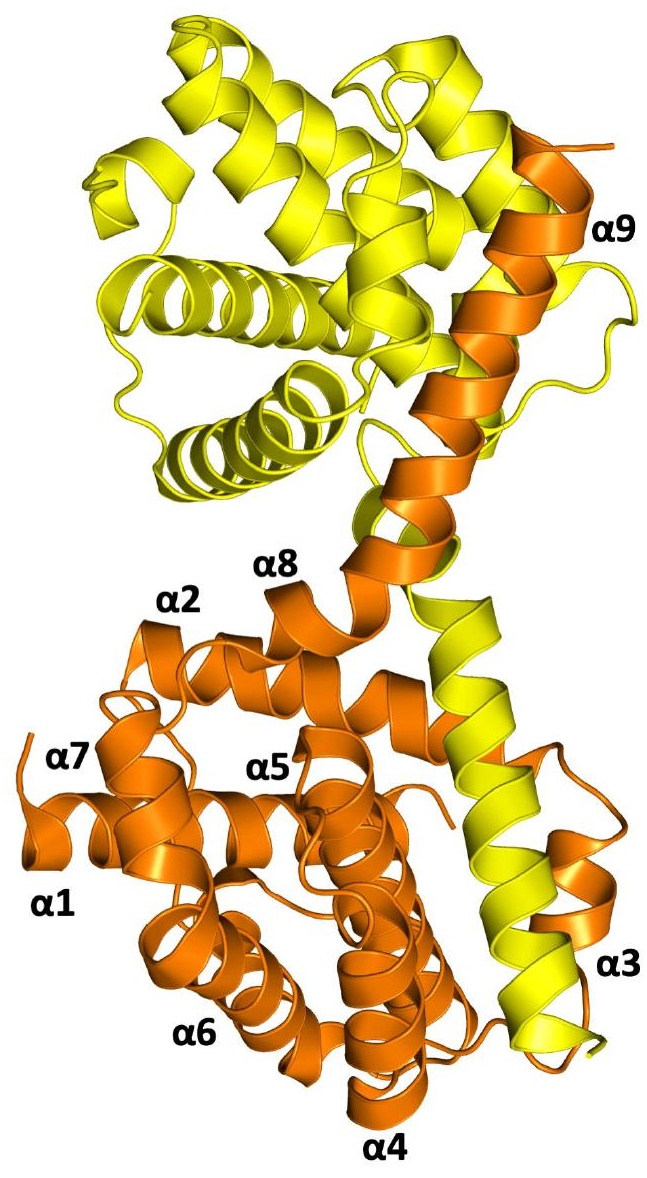

ipBax 